\title{
Anti-CD47 Antibody As a Targeted Therapeutic Agent for Human Lung Cancer and Cancer Stem Cells
}

\begin{abstract}
Liang Liu'1,2,3,4t, Lin Zhang ${ }^{1,3,4 t}$, Lin Yang ${ }^{5}$, Hui Li ${ }^{1,3,4}$, Runmei Li ${ }^{2,3,4}$, Jinpu Yu ${ }^{1,3,4}$, Lili Yang ${ }^{1,3,4}$, Feng Wei ${ }^{1,3,4}$, Cihui Yan ${ }^{1,3,4}$, Qian Sun 1,3,4, Hua Zhao ${ }^{1,3,4}$, Fan Yang ${ }^{2,3,4}$, Hao Jin ${ }^{1,3,4}$, Jian Wang ${ }^{1,3,4}$, Shizhen Emily Wang ${ }^{1,3,4,6}$ and Xiubao Ren $^{1,2,3,4 *}$

${ }^{1}$ Department of Immunology, Tianjin Medical University Cancer Institute and Hospital, Tianjin, China, ${ }^{2}$ Department of Biotherapy, Tianjin Medical University Cancer Institute and Hospital, Tianjin, China, ${ }^{3}$ National Clinical Research Center of Cancer, Tianjin, China, ${ }^{4}$ Key Laboratory of Cancer Immunology and Biotherapy, Tianjin, China, ${ }^{5}$ State Key Laboratory of Experimental Hematology, Peking Union Medical College, Institute of Hematology and Blood Diseases Hospital, Chinese Academy of Medical Sciences, Tianjin, China, ${ }^{6}$ Department of Pathology, University of California, San Diego, CA, USA
\end{abstract}

\section{OPEN ACCESS}

Edited by:

Sherven Sharma,

VA Greater Los Angeles Healthcare System (NHA), USA

Reviewed by:

Nejat K. Egilmez,

University of Louisville, USA

Giulio Cesare Spagnoli,

University of Basel, Switzerland

${ }^{*}$ Correspondence: Xiubao Ren renxiubao@tjmuch.com

tThese authors have contributed equally to this work.

Specialty section: This article was submitted to

Cancer Immunity and

Immunotherapy, a section of the journal

Frontiers in Immunology

Received: 06 February 2017 Accepted: 22 March 2017

Published: 21 April 2017

Citation:

Liu L, Zhang L, Yang L, Li H, Li R, Yu J, Yang L, Wei F, Yan C, Sun $Q$,

Zhao $H$, Yang $F$, Jin $H$, Wang J,

Wang SE and Ren X (2017)

Anti-CD47 Antibody As a Targeted

Therapeutic Agent for Human Lung

Cancer and Cancer Stem Cells.

Front. Immunol. 8:404.

doi: 10.3389/fimmu.2017.00404
Accumulating evidence indicates that a small subset of cancer cells, termed the tumorinitiating cells or cancer stem cells (CSCs), construct a reservoir of self-sustaining cancer cells with the characteristic ability to self-renew and maintain the tumor mass. The CSCs play an important role in the tumor initiation, development, relapse, metastasis, and the ineffectiveness of conventional cancer therapies. CD47 is a ligand for signal-regulatory protein- $\alpha$ expressed on phagocytic cells and functions to inhibit phagocytosis. This study was to explore if the expression of CD47 is the mechanism used by lung cancer cells, especially CSCs, to escape phagocytosis in vitro and in vivo. Here, we selected CD133 as the marker for lung CSCs according to previous reports. We analyzed lung cancer and matched adjacent normal (non-tumor) tissue and revealed that CD47 is overexpressed on lung cancer cells, especially on lung CSCs. The mRNA expression levels of CD47 and CD133 correlated with a decreased probability of survival for multiple types of lung cancer. Blocking CD47 function with anti-CD47 antibodies enabled macrophage phagocytosis of lung cancer cells and lung CSCs. Anti-CD47 antibodies inhibited tumor growth in immunodeficient mouse xenotransplantation models established with lung cancer cells or lung CSCs and improved survival in tumor-bearing animals. These data indicate that CD47 is a valid target for cancer therapies, especially for anti-CSC therapies.

Keywords: CD47, antibody, therapeutic agent, human lung cancer, cancer stem cells

\section{INTRODUCTION}

Tumors are organized in a cellular hierarchy maintained by a small pool of self-renewing cancer stem cells (CSCs) or tumor-initiating cells (TICs), which must be removed to eliminate the tumor, according to the TIC or CSC model $(1,2)$. Candidate TICs have been prospectively isolated from a variety of solid tumors, including lung (3-6), breast $(7,8)$, brain (9), colorectal $(10,11)$, head and neck (12), pancreatic (13), prostate (14), and melanoma (15), based primarily on the expression of $\mathrm{CD} 44, \mathrm{CD} 133, \mathrm{ALDH}$, and $\mathrm{ABCB} 5$ that have been recognized as markers for CSC enrichment. 
For the development of CSC-targeted therapies, it is necessary to identify molecules and pathways that are preferentially expressed in CSCs and critical for cancer pathogenesis and stemness.

CD47 is a widely expressed transmembrane protein with numerous functions (16). It functions as a ligand for signalregulatory protein- $\alpha(\operatorname{SIRP} \alpha)$, a protein expressed on phagocytes, such as macrophages and dendritic cells (17). SIRP $\alpha$ initiates a signaling cascade through binding CD47, which results in the inhibition of phagocytosis (16). Blood cells, such as red blood cells, platelets, and lymphocytes, require CD47 expression on their membranes to protect themselves from rapid elimination by splenic macrophages (18-20). CD47 is upregulated in the migrating hematopoietic stem cells (HSCs), which protect themselves from phagocytosis by phagocytes as they pass through phagocytelined sinusoids (21). As such, CD47 expression levels predict the probability of HSCs to be phagocytosed during the circulation (21). CD47 is expressed at even higher levels on leukemia stem cells (LSCs) than their normal counterparts. Higher expression levels of CD47 on human LSCs contribute to pathogenesis by inhibiting their phagocytosis through the interaction of CD47 with an inhibitory receptor on phagocytes (22). Accumulating evidence suggests that CD47 expression on human solid tumor cells and especially CSCs is a common mechanism through which these cells protect themselves from phagocytosis, allowing tumor cell proliferation and metastasis (23-28).

This study was to explore whether the expression of CD47 is the mechanism used by lung cancer cells, especially CSCs, to escape phagocytosis in vitro and in vivo. We selected CD133 as a marker for lung CSCs (3-6). We show that CD47 is highly expressed on lung cancer cells and lung CSCs compared to its normal counterparts. Increased CD47 and CD133 expression levels in lung cancer patients correlated with a decreased probability of survival. Monoclonal antibodies targeting CD47 enabled the phagocytosis of patient-derived lung cancer cells and CSCs in vitro and inhibited the in vivo growth of xenografted tumors developed from patient-derived lung cancer cells or CSCs. These results indicate that $\mathrm{CD} 47$ is a critical regulator of innate immune surveillance and show that CD47 is a valid target for lung CSC therapies.

\section{MATERIALS AND METHODS}

\section{Cell Lines}

The lung adenocarcinoma (AC) cell line A549 and lung squamous cell carcinoma (SCC) cell line NCI-H520 were obtained from the American Type Culture Collection. The LC3 and LC9 cell lines were generated from patients with small cell lung carcinoma (SCLC) and AC, respectively, by culturing bulk cells in vitro with IMDM supplemented with $10 \%$ human serum for 2 months.

\section{Human Samples}

Tumor and matched adjacent normal (non-tumor) tissue specimens were defined by pathologists at Tianjin Medical University Cancer Institute and Hospital. Tumor specimens were cut to 1-2 $\mathrm{mm}^{3}$ masses and then enzymatically dissociated in Medium 199 containing collagenase III and DNase I (Sigma-Aldrich,
St. Louis, MO, USA) at $37^{\circ} \mathrm{C}$ for $2-3 \mathrm{~h}$, until single-cell suspension was obtained. Cells were then washed twice with PBS and filtered through a $70-\mu \mathrm{m}$ filter.

\section{Flow Cytometry Analysis}

For analysis of human lung cancer cell lines, primary tumor cells, and matched adjacent normal (non-tumor) cells, the following antibodies were used: CD45-APC, CD31-APC, CD47-Percp/Cy5 (BioLegend, San Diego, CA, USA) and ESA-FITC, CD133/1-PE (MiltenyiBiotec, Via Persicetana, Bologna, Italy). For analysis of mouse HSC in bone marrow, the following antibodies were used: Lin (V450 Mouse Lineage antibody Cocktail) (BD Bioscience, San Diego, CA, USA) and C-Kit-PE/Cy7, Sca-1-APC (BioLegend). Other antibodies include anti-mouse F4/80-PE/Cy7 and antihuman CD14-PE/Cy7 (Ebiosciences, San Diego, CA, USA). FACS analysis and cell sorting were performed on a BDFACSAria (Becton Dickinson) cell-sorting system under 20 psi with a $100-\mu \mathrm{m}$ nozzle.

\section{Evaluation of Prognostic Value of CD47 and CD133 in Lung Cancer}

Tianjin Medical University Cancer Institute and Hospital pathologists defined 317 patients tumor and 31 adjacent normal (non-tumor) tissue specimens. Total RNA of these tissues were provided by the National Clinical Research Center of Cancer of China. The mean of the 31 adjacent normal tissues RNA was regarded as the control RNA. The following primer sequences are used for PCR: CD47 cDNA F: ATC CGG TGG TAT GGA TGA GA, CD47 cDNA R: GGC AAT GAC GAA GGA GGT TAA, CD133 cDNA F: GCT TTG CAA TCT CCC TGT TG, CD133 cDNA R: TTG ATC CGG GTT CTT ACC TG. Real-time PCR was performed on ABI-9700. The definitions of overall survival (OS) and progression-free survival (PFS) were based on the RECIST. OS was calculated from the time of initiation therapy until death, and living patients were censored at the time of last contact. PFS was calculated from the time of initiation therapy until first progression, and patients alive and in a stable condition were censored at the time of last contact. The $\chi^{2}$ test and Fisher exact test were used for binary variable comparisons. The Mann-Whitney $U$ test was used for median comparisons. The distributions of survival times and rates were estimated using the Kaplan-Meier method; the median survival times with 95\% confidence intervals were reported. Associations between survival and potential prognostic factors were assessed using the log-rank test in a univariate analysis. The Cox proportional hazards model was undertaken in multivariable analyses by using the Forward-LR method with a significance level of 0.15 for entering and removing variables. In univariate evaluations of the prognostic impact of a continuous variable, the optimal cutoff was determined using the ROC method. A $P$ value less than 0.05 using two-sided tests indicates significance. All calculations were performed using the SPSS 16.0 software.

\section{Preparation of Mouse and Human Macrophages}

$\mathrm{BALB} / \mathrm{c}$ mouse bone marrow mononuclear cells were harvested and grown in IMDM containing 10\% FBS supplemented with 
$10 \mathrm{ng} / \mathrm{mL}$ recombinant murine macrophage colony-stimulating factor (Peprotech, Rocky Hill, NJ, USA) for 7-10 days to allow terminal differentiation of monocytes to macrophages. Human peripheral blood mononuclear cells were prepared from discarded normal blood from the Tianjin Medical University Cancer Institute and Hospital. Monocytes were isolated by adhering mononuclear cells to culture plates for $1 \mathrm{~h}$ at $37^{\circ} \mathrm{C}$, after which non-adherent cells were removed by washing. The remaining cells were $>95 \%$ CD 14 and CD 11 b positive. Adherent cells were then incubated in IMDM plus 10\% human serum for 7-10 days to allow terminal differentiation of monocytes to macrophages.

\section{In Vitro Phagocytosis Assay}

Bone marrow-derived macrophages of $\mathrm{BALB} / \mathrm{c}$ mice or peripheral blood-derived macrophages of patients were prepared and harvested by incubation in trypsin/EDTA (Gibco) for $5 \mathrm{~min}$ and gentle scraping. A total of $5 \times 10^{4}$ macrophages were plated per well in a 24 -well plate. Tumor cells were marked with $2.5 \mu \mathrm{M}$ carboxyfluoresceinsuccinimidyl ester (CFSE) according to the manufacturer's protocol (Invitrogen). Macrophages were incubated in serum-free IMDM for $4 \mathrm{~h}$ before adding $2 \times 10^{5} \mathrm{CFSE}-$ marked live tumor cells. The indicated antibodies $(10 \mu \mathrm{g} / \mathrm{mL})$ were added and incubated for $2 \mathrm{~h}$ at $37^{\circ} \mathrm{C}(26)$. After coincubation, wells were washed thoroughly with IMDM three times and subsequently imaged with fluorescence microscopy. The phagocytic index was calculated as the number of phagocytosed CFSEpositive cells per 100 macrophages. At least 200 macrophages were counted per well.

\section{Therapeutic Antibodies}

The therapeutic antibodies and controls included anti-human CD47 B6H12.2 (Abcam, Cambridge, MA, USA); anti-human SIRP $\alpha / \beta$ antibodySE5A5; anti-mouseCD47 MIAP301 (Biolegend); mouse IgG1 isotype; rat IgG2 isotype; anti-HLA-A, B, and C (Ebiosciences); anti-mouse SIRP $\alpha$; and P84 (BD Pharmingen).

\section{Generation of Luciferase-Positive Cell Lines and Luciferase Imaging Analysis}

Lentivirus vector pUbi-MCS-LUC-IRES-puromycin was purchased from Shanghai (GENE, Shanghai, China). Lung cancer cell lines and primary lung cancer cells were transduced with the lentivirus and selected by puromycin following standard protocols and grown for several generations to ensure stability of the transgenes.

\section{In Vivo Precoating Engraftment Assay}

Luciferase-expressing human lung cancer cell lines and primary lung cancer cells and their FACS-purified CSCs were precoated with $10 \mu \mathrm{g} / \mathrm{mL}$ IgG1 isotype control or anti-CD47 B6H12.2 antibody for half an hour in vitro. A total of $5 \times 10^{6}$ precoated lung cancer cells or $1 \times 10^{4}$ precoated lung CSCs were transplanted subcutaneously into NOD/SCID mice. All experiments involving mice were performed according to Tianjin Medical University Cancer Institute and Hospital animal guidelines. The tumor size in mice was measured by bioluminescence.

\section{In Vivo Antibody Treatment Xenograft Model}

Luciferase-labeled A549 cells or LC3 primary lung cancer cells were injected subcutaneously at $5 \times 10^{6}$ into the 6 - to 8 -week-old NOD/SCID mice. Those mice with luciferase-positive tumors after 5-6 weeks were given daily intraperitoneal injections of $400 \mu \mathrm{g}$ mouse IgG1 control or anti-human CD47 B6H12.2 antibody for 4 weeks. Antibody treatment was then stopped, and mice were followed for survival analysis. Luciferase-labeled NCI-H520 CSCs or LC9 primary lung CSCs were transplanted subcutaneously at $1 \times 10^{4}$ into the 6 - to 8 -week-old NOD/SCID mice. Those mice with luciferase-positive lung cancer after 9-10 weeks were given daily intraperitoneal injections of $400 \mu \mathrm{g}$ mouse IgG1 control or anti-human CD47 B6H12.2 antibody for 4 weeks. Antibody treatment was then stopped, and mice were followed for survival analysis.

\section{RESULTS}

\section{CD47 Expression Is Increased on Lung Cancer Cells and Lung CSCs Compared to Their Normal Counterparts}

We evaluated CD47 expression on dissociated primary lung tumor cells (tumor cells) and matched adjacent normal cells (normal cells) from human patients by flow cytometry (FACS). $\mathrm{CD}^{2} 5^{-}, \mathrm{CD}^{-} 1^{-}, \mathrm{DAPI}^{-}$, and $\mathrm{ESA}^{+}$were used as the markers to detect viable lung tumor cells and normal cells. CD47 expression was detected on lung tumor cells and normal cells (Figure 1A) and on lung CSCs $\left(\mathrm{CD} 133^{+}\right)$and normal stem cells $\left(\mathrm{CD} 133^{+}\right)$ (Figure 1B). Tumor cells expressed higher levels of CD47 than normal cells (Figure 1C). In addition, CSCs expressed higher levels of CD47 than normal stem cells (Figure 1C). These samples included lung AC, lung SCC, and SCLC (Figure S1 in Supplementary Material). Across different lung cancer subtypes, we found varying levels of CD47 expression that was significantly different within each lung cancer subtype (Figure 1D).

\section{Increased CD47 and CD133 Expression Correlate with a Worse Clinical Prognosis}

To determine whether CD47 mRNA level serves as a prognostic factor in human lung cancers, we retrospectively analyzed gene expression data of 317 lung cancer patients including 100 AC (Table S1 in Supplementary Material), 147 SCC (Table S2 in Supplementary Material), and 70 SCLC (Table S3 in Supplementary Material). Distributions of relative CD47 and CD133 mRNA expression levels and clinical characteristics were shown in Tables S1-S3 in Supplementary Material. In a multivariable analysis, stratification of patients into " $C D 47$ high" and "CD47 low" groups indicated that high CD47 mRNA expression levels could decrease the OS and PFS in patients with AC (Figure 2A), SCC (Figure 2B), and SCLC (Figure 2C). We also detected CD133 mRNA expression levels in the 317 lung cancer patients. In a multivariable analysis, a higher CD133 mRNA expression level was associated with a decreased probability of OS and PFS in patients with AC (Figure 2D), SCC 


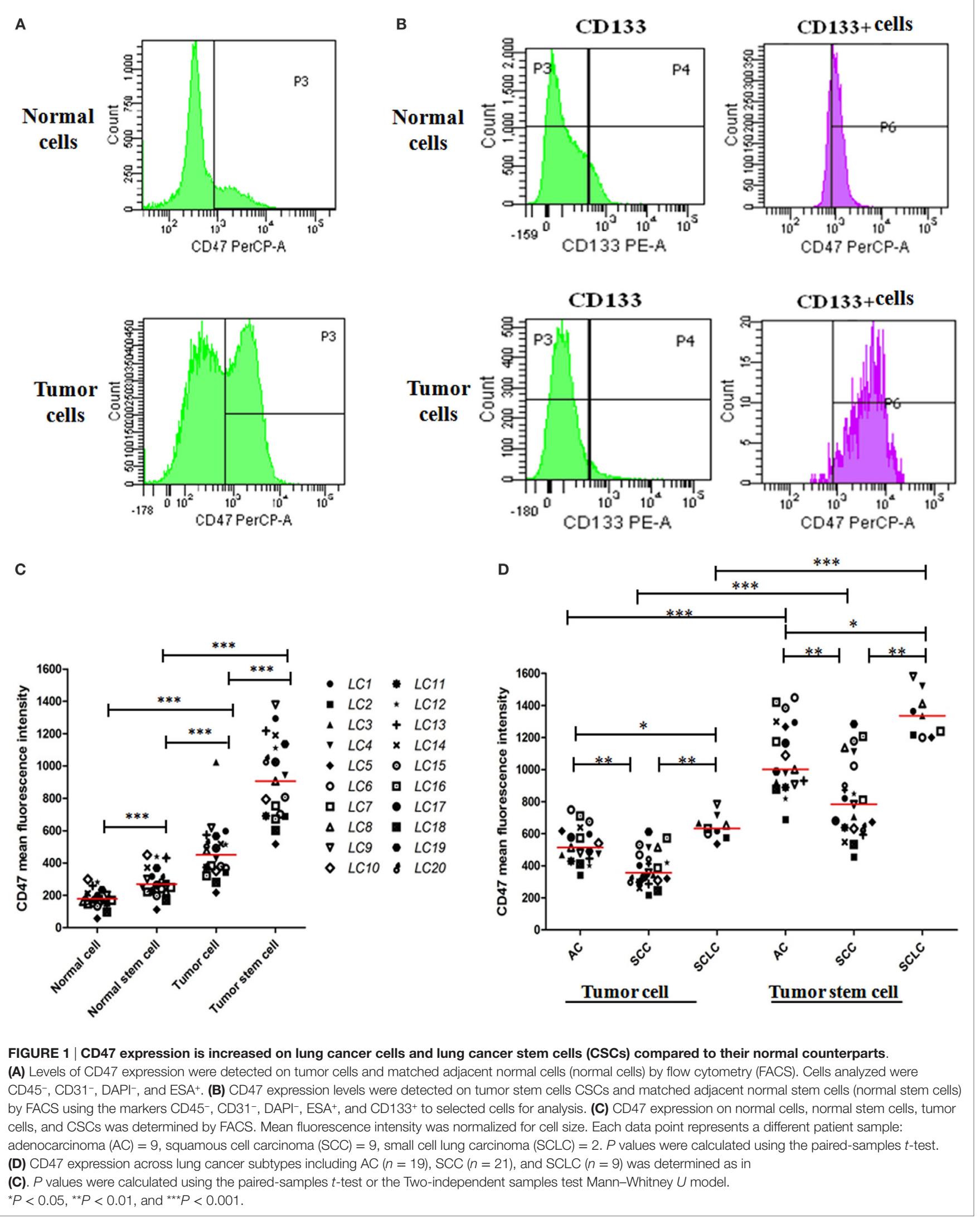


(Figure 2E), and SCLC (Figure 2F). The results of multivariable analysis in AC, SCC, and SCLC were shown in Tables S4-S6 in Supplementary Material. We extended our analysis to doublepositive patients. The results show that CD47 and CD133 mRNA double higher expression levels can decrease the OS and PFS in patients with AC (Figure S2A in Supplementary Material), SCC (Figure S2B in Supplementary Material), and SCLC (Figure S2C in Supplementary Material). These results reveal that $C D 47$ and CD133 expression levels may be independent prognostic factors in lung cancer patients. We further analyzed the expression correlation of CD47 and CD133 mRNA in the 317 lung cancer patients. Significant positive correlation was detected between CD47 mRNA and CD133 mRNA expression levels in AC, SCC, and SCLC patients (Figure 2G).
A

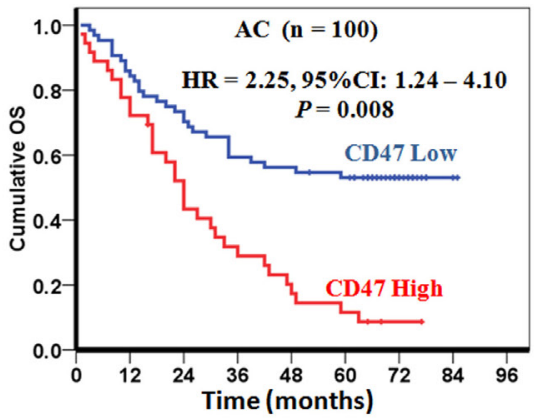

B

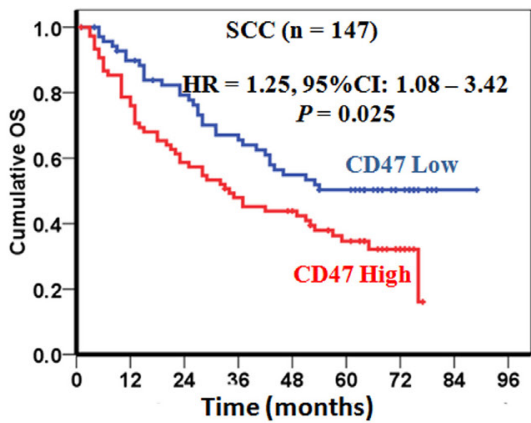

C

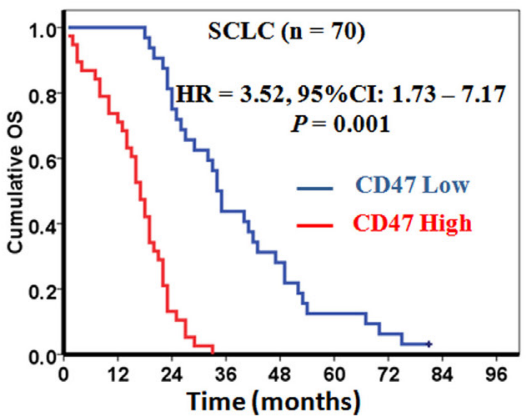

D

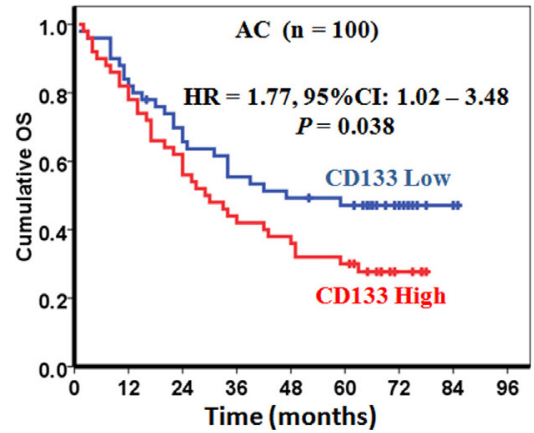

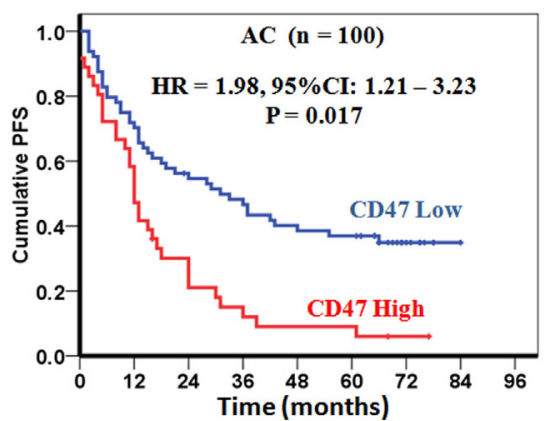
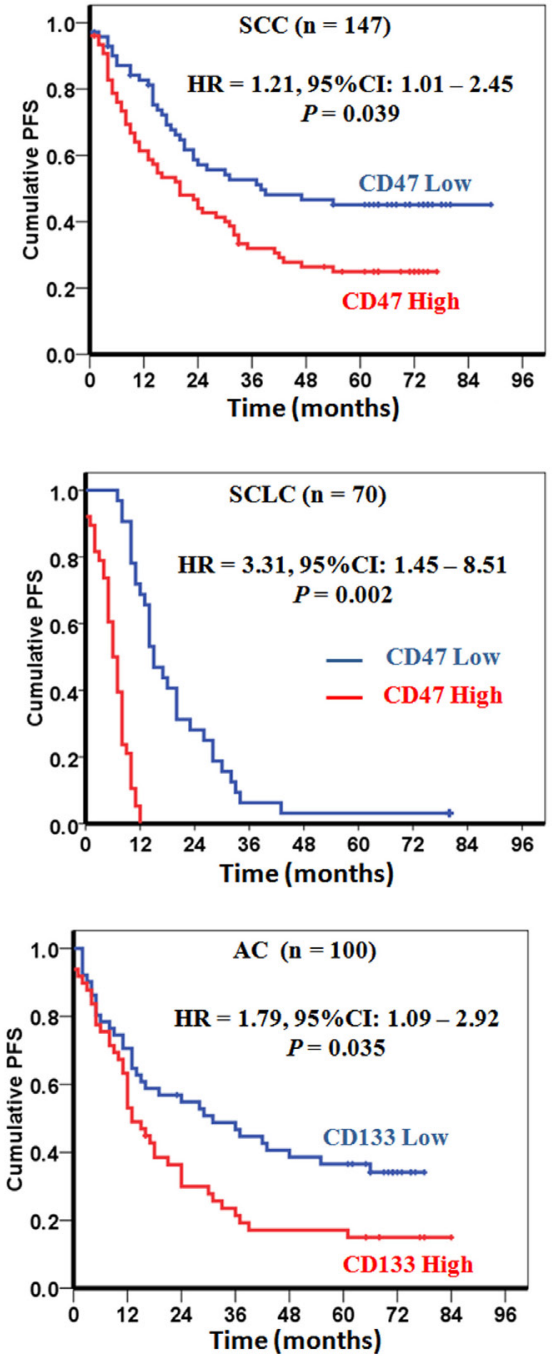
E

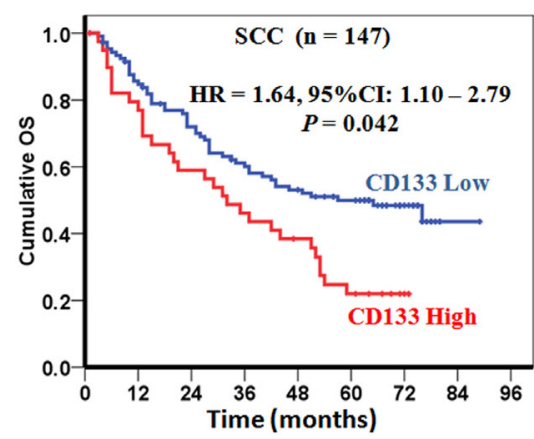

$\mathbf{F}$

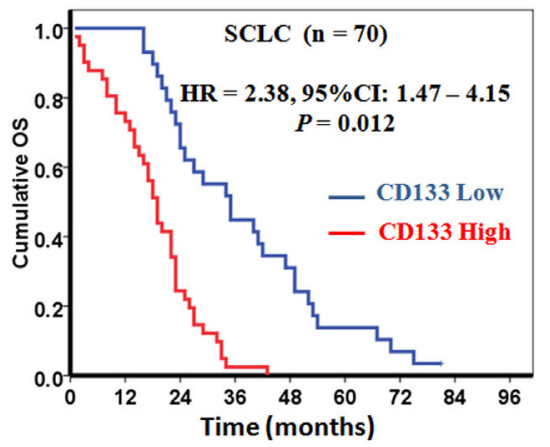

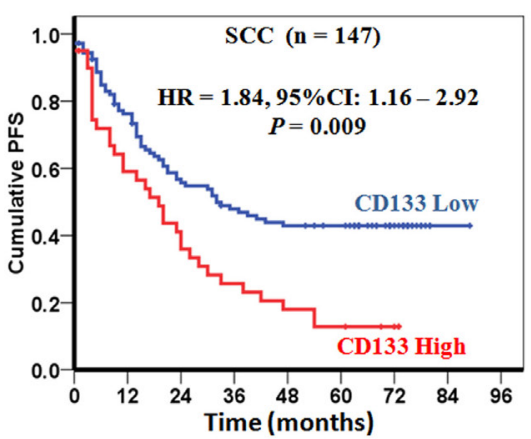

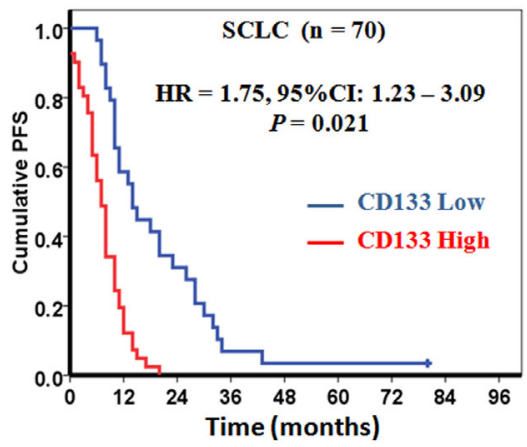

G

$\mathrm{AC}$

SCC

SCLC
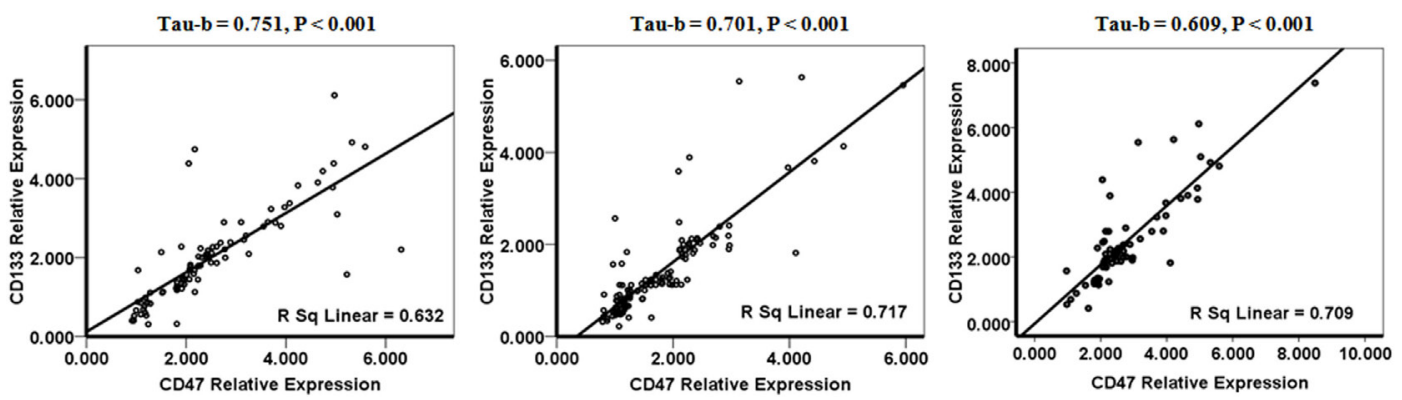

FIGURE 2 | Increased CD47 and CD133 expressions correlate with a worse clinical prognosis. (A-C) CD47 mRNA level is an independent prognostic factor in lung cancers. Increased levels of CD47 mRNA were correlated with decreased probability of overall survival (OS) and progression-free survival (PFS) of patients with adenocarcinoma (AC) (A), squamous cell carcinoma (SCC) (B), and small cell lung carcinoma (SCLC) (C). (D-F) CD133 mRNA level is an independent prognostic factor in lung cancers. Prognostic impact of CD133 mRNA level is shown as the correlation with OS and PFS of patients with AC (D), SCC (E), and SCLC (F). $P$ values were calculated using the Cox regression forward-LR model (A-F). (G) CD47 mRNA levels were positive correlation with the CD133 mRNA levels in patients with AC, SCC, and SCLC. $P$ values were calculated using the Bivariate Correlations Kendall's tau-b model.

\section{Anti-CD47-Blocking Antibodies Enable Phagocytosis of Lung Cancer Cells and Lung CSCs by Macrophages In Vitro}

We first tested the ability of anti-human CD47 antibody to enable phagocytosis of human lung cancer cell lines and primary lung cancer cells by human and mouse macrophages in vitro. Incubation of lung cancer cells in the presence of isotypematched IgG1 control or anti-HLA antibody did not result in significant phagocytosis by human and mouse macrophages. In contrast, human and mouse macrophages could efficiently phagocytose lung cancer cells treatment with the anti-human
CD47-blocking antibody B6H12.2 (Figures 3A,B). Disruption of the CD47-SIRP $\alpha$ interaction with anti-human or anti-mouse SIRP $\alpha$ antibody also resulted in significant phagocytosis of lung cancer cells (Figure 3B). Next, we repeated the in vitro phagocytosis assays with lung CSCs. Purified lung CSCs were isolated from lung cancer cell lines and primary lung cancer cells by FACS (Figure 1B). Incubation of purified lung CSCs in the presence of isotype-matched IgG1 control or anti-HLA antibody did not result in significant phagocytosis by human and mouse macrophages; however, lung CSCs treated with the anti-human CD47-blocking antibody B6H12.2 were significantly phagocytosed by human and mouse macrophages (Figures 3C,D). Disruption of the 
CD47-SIRP $\alpha$ interaction with anti-human or anti-mouse SIRP $\alpha$ antibody also resulted in significant phagocytosis of purified lung CSCs (Figure 3D). These results suggest that CD47 is a feasible therapy target and that anti-human CD47-blocking antibody may serve as an effective therapeutic agent to inhibit lung cancer growth by enabling macrophages to eliminate both CSCs and their differentiated progeny.

We further detected whether the anti-human CD47 antibody can influence the apoptosis or proliferation of lung cancer cells or lung CSCs. Lung cancer cells or lung CSCs were incubated with the indicated soluble antibodies in suspension for $8 \mathrm{~h}$. Anti-human CD47 antibody did not increase the apoptosis of lung cancer cells or CSCs compared to IgG isotype or anti-HLA antibodies (Figure 3E; Figure S3A in Supplementary Material). Similar negative results were observed with anti-human SIRP $\alpha$ and anti-mouse $\operatorname{SIRP} \alpha$ (Figure 3E). Then, lung cancer cells or lung CSCs were treated with the indicated soluble antibodies in adherence for $48 \mathrm{~h}$. Anti-human CD47, anti-human SIRP $\alpha$, or anti-mouse SIRP $\alpha$ has no effect on the proliferation of lung cancer cells (Figures S3B,C in Supplementary Material). We also investigated whether NK cells could mediate tumor elimination by anti-CD47 antibody in vitro. By utilizing human NK cells $\left(\mathrm{CD}^{-}{ }^{-} \mathrm{CD} 56^{+} \mathrm{CD}^{+}\right)$as effectors, anti-CD47 antibody did not induce increased ADCC of lung cancer cell line cells or primary
A

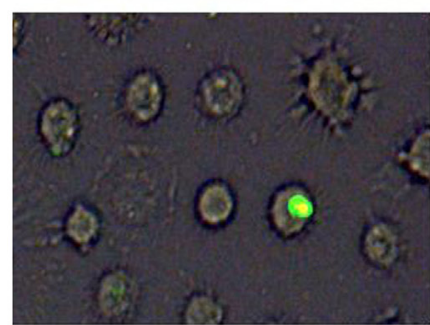

- Human macrophage
Anti-HLA

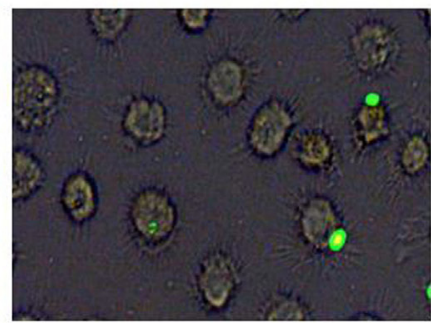

- Patient'stumor cell
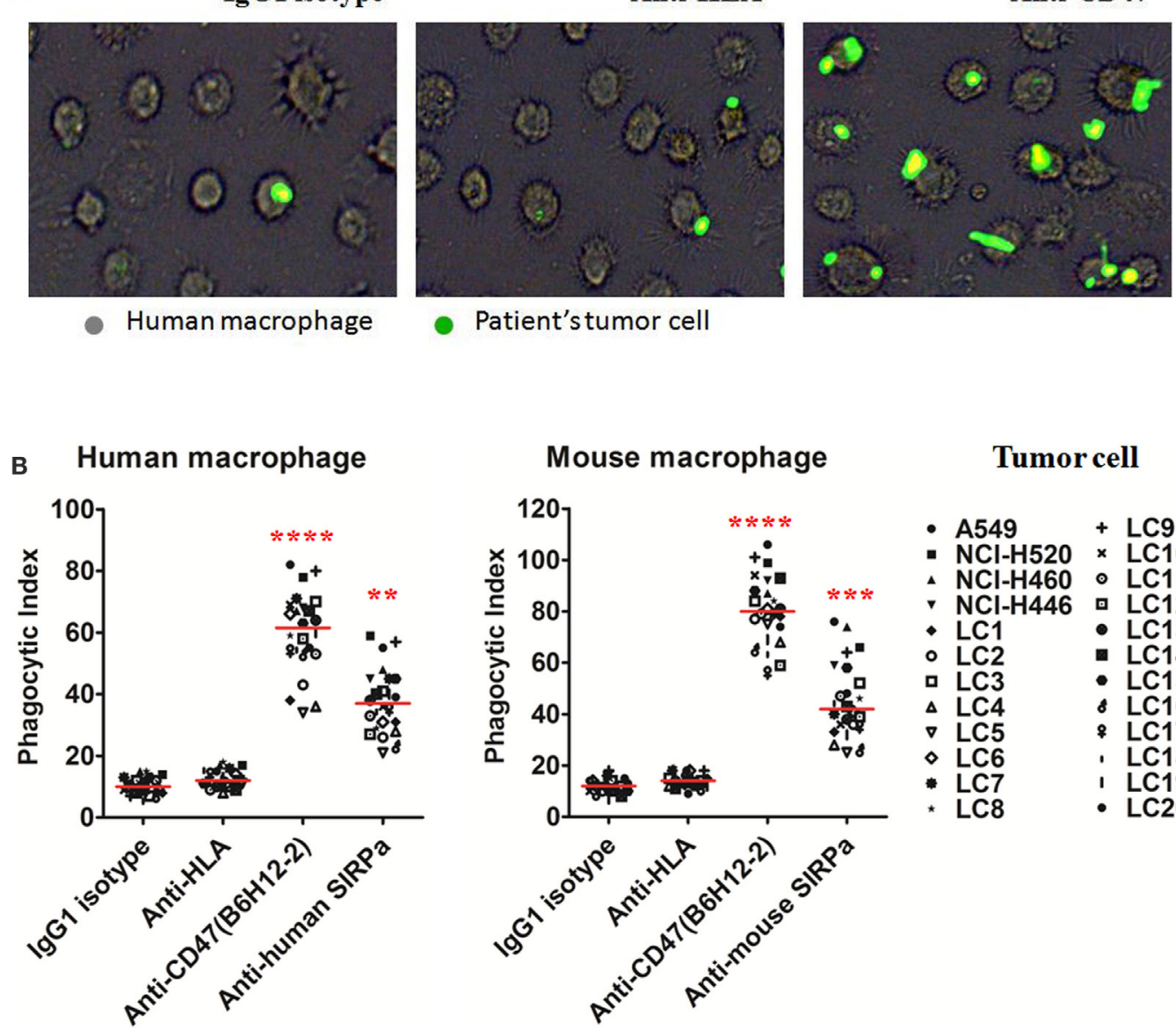

Tumor cell

C

IgG1 isotype

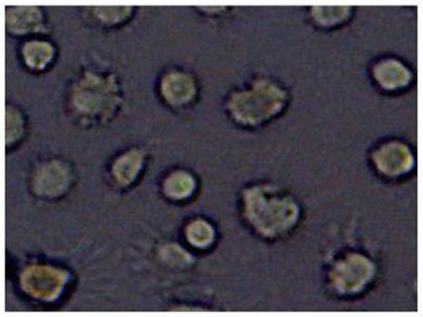

- Human macrophage

- $\mathrm{A549}+\mathrm{LC9}$

- NCl-H520 × LC10

$\triangle \mathrm{NCl}-\mathrm{H} 460 \circ \mathrm{LC} 11$

- NCl-H446 a LC12

- LC1 1 LC13

- LC2

- LC3 LC15

$\triangle$ LC4 \& LC16

$\nabla$ LC5 \& LC17

$\checkmark$ LC6 , LC18

* LC8 8 LC20
Anti-CD47

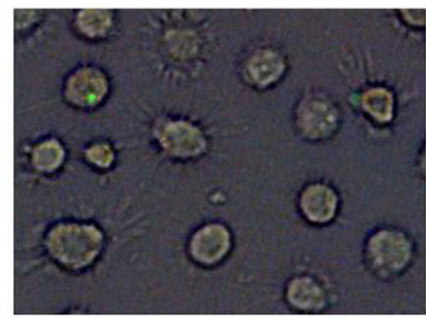

Patient'stumor stem cell

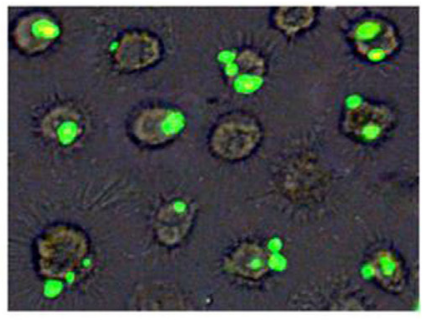

FIGURE $3 \mid$ Continued 

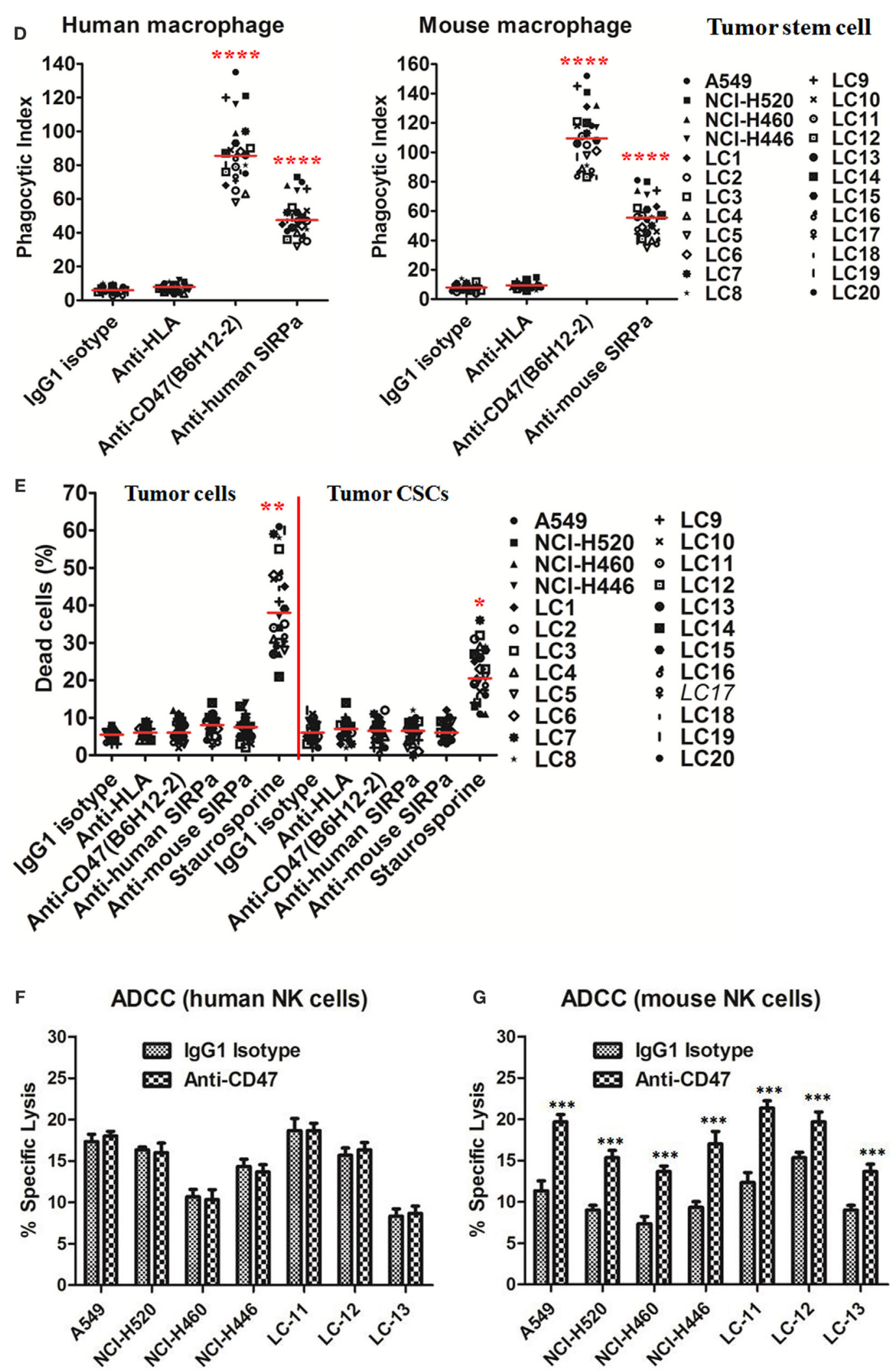

FIGURE 3 | Continued 
FIGURE 3 | Continued

Blocking antibodies against CD47 enable phagocytosis of lung cancer cells and lung cancer stem cells (CSCs) by macrophages in vitro

(A,B) Carboxyfluoresceinsuccinimidyl ester (CFSE)-labeled lung cancer cells were incubated with human macrophages or mouse macrophages and the indicated antibodies and examined by immunofluorescence microscopy to detect phagocytosis. (A) Images from a representative lung cancer sample are shown.

(B) Phagocytic indices of primary human lung cancer cells and lung cancer cell lines were determined using human (left) and mouse (right panel) macrophages. (C,D) CFSE-labeled lung CSCs were incubated with human macrophages or mouse macrophages as well as the indicated antibodies and examined by immunofluorescence microscopy to detect phagocytosis. (C) Images from a representative lung CSCs sample are shown. (D) Phagocytic indices of primary human lung CSCs and lung cancer cell lines CSCs were determined using human (left) and mouse (right panel) macrophages. (E) Antibody-induced apoptosis was tested by incubating lung cancer cells or lung CSCs with the indicated antibodies or staurosporine without macrophages and assessing the percentage of apoptotic and dead cells (\% annexin $\mathrm{V}$ and/or PI positive). (F,G) Chromium release assays measuring ADCC were performed in triplicate with human (F) and mouse (G) at an effector:target ratio of 20:1, and percent specific lysis is reported. Antibodies were incubated at $10 \mu \mathrm{g} / \mathrm{mL}$. $P$ values were calculated using the two-independent samples test Mann-Whitney $U$ model. ${ }^{\star} P<0.05,{ }^{\star \star} P<0.01$, ${ }^{\star \star \star} P<0.001$, and ${ }^{\star \star \star \star} P<0.0001$.

patients tumor cells compared to IgG1 isotype control (Figure 3F). As anti-CD47 antibody (B6H12.2) is a mouse IgG1 isotype, we repeated these assays with mouse NK cells $\left(\mathrm{CD}^{-}{ }^{-} \mathrm{DX} 5^{+}\right)$. Anti-CD47 antibody caused increased ADCC of these cells compared to isotype control (Figure 3G). These data indicate that the mechanism of anti-CD47 antibody to inhibit cancer cells or CSC growth is unlikely to be that these antibodies induce apoptosis of lung cancer cells or CSCs that are then secondarily phagocytosed or directly inhibit proliferation of lung cancer cells.

\section{Ex Vivo Coating of Lung Cancer Cells and Lung CSCs with an Anti-CD47 Antibody Inhibits Tumor Engraftment}

Next, we detected the ability of anti-CD47-blocking antibody to eliminate lung cancer cells and lung CSCs in vivo by two different treatment strategies. First, the effect of ex vivo anti-CD47 antibody coating on the engraftment of human lung cancer cells and lung CSCs was tested. Luciferase-expressing A549 cell line was precoated ex vivo with anti-CD47 or IgG1 isotype antibody and transplanted subcutaneously into NOD/SCID mice. After 8 weeks, all (six of six) mice in control IgG treatment group developed large tumors, but no tumors were detected in the mice treated with anti-human CD47 antibody (Figure 4A; Figure S4A in Supplementary Material). We repeated the in vivo engraftment experiment with CSCs isolated from lung cancer cell line. FACS-purified luciferase-expressing NCI-H520 CSCs were precoated ex vivo with anti-CD47 or IgG1 isotype antibody and injected subcutaneously into NOD/SCID mice. After 12 weeks, all (six of six) mice in the control IgG treatment group developed large tumors, whereas no tumors were detected in the anti-human CD47 antibody-treated mice as evidenced by bioluminescence imaging (Figure 4B). In addition to these cell lines, we also examined patient-derived primary lung tumor cells for their ability to engraft NOD/SCID mice. Similar to the results with the cell lines, ex vivo coating of these primary tumor cells (Figure 4C) and primary CSCs (Figure 4D; Figure S4B in Supplementary Material) with anti-CD47 antibody, but not controls, resulted in complete inhibition of subcutaneous engraftment.

We analyzed $\mathrm{ESA}^{+} \mathrm{CD} 133^{+}$cells in primary tumor cells and showed that there were $0.5-11.6 \% \mathrm{ESA}^{+} \mathrm{CD} 133^{+}$cells in the primary tumor cells (median $4.6 \%$ ). There were more than $95 \%$ $\mathrm{ESA}^{+} \mathrm{CD} 133^{-}$non-CSCs in tumors and $\mathrm{ESA}^{+} \mathrm{CD}^{-} 33^{+} \mathrm{CSC}$ were no more than $5 \%$. Therefore, the antitumor effect obtained in the xenograft model may be mediated majorly by anti-CD47 antibody targeting $\mathrm{ESA}^{+} \mathrm{CD} 133^{-}$tumor cells.

\section{Therapy with Anti-CD47 Antibody Eliminates Lung Cancer Cells and Lung CSCs in the Xenotransplant Models}

In the second treatment strategy, mice were first engrafted with lung cancer cells or lung CSCs and then administered antiCD47 B6H12.2 antibody therapy. First, luciferase-expressing A549 cells were transplanted subcutaneously into NOD/SCID mice. Five weeks later, these mice were administered daily by intraperitoneal injections with either IgG1 isotype antibody or anti-human CD47 B6H12.2 antibody. Anti-CD47 antibody treatment decreased the tumor burden in these mice and significantly prolonged survival compared to control IgG1 (Figures 5A,B). Next, we purified the CSCs from the luciferaseexpressing NCI-H520 cell line by FACS. Luciferase-expressing NCI-H520 CSCs were transplanted subcutaneously into NOD/ SCID mice. Twelve weeks later, these mice were administered daily with either IgG1 isotype antibody or anti-human CD47 B6H12.2 antibody. Treatment with anti-human CD47 antibody inhibited CSC-initiated tumor growth as evidenced by bioluminescence imaging. Importantly, the mice treated with antiCD47 indicated a dramatic increase in survival (Figures 5C,D). We also repeated the in vivo engraftment experiments with primary lung cancer cells and primary lung CSCs. In these two additional xenotransplantation models, anti-CD47 antibody treatment eliminated all of the primary lung cancer cells (Figures 5E,F) and primary lung CSCs (Figures 5G,H) in mice and significantly prolonged survival compared to IgG control (Figures 5E-H).

We further tested whether anti-human CD47 antibody can increase the number of macrophages in the tumor tissues in the xenotransplant models. Primary LC12 cells were subcutaneously transplanted into the NOD/SCID mice. When the sizes of the tumors reached $\sim 200 \mathrm{~mm}^{3}$ after 6 weeks, $400 \mu \mathrm{g}$ IgG1 isotype antibody or anti-human CD47 B6H12.2 antibody was intraperitoneally injected into the mice. After $48 \mathrm{~h}$, the tumors were collected from the mice and disassociated for FACS $(n=4$ per antibody condition). The results indicated that numbers of macrophages in the tumor tissues in anti-CD47-treated mice were significantly higher compared to the IgG1 isotype-treated control mice (Figure S5 in Supplementary Material). These data collectively indicate that anti-CD47 antibodies can recruit 
macrophages into the tumor microenvironment, dramatically inhibiting the growth of lung cancer cells and eliminated lung CSCs, thereby blocking the ability of CD47 to transmit the "don't-eat-me" signal to macrophages.

\section{Anti-CD47 Antibody Exhibited No Significant Toxic Effect except Temporary White Blood Cell Reduction and Anemia}

CD47 is expressed at low levels on most normal tissues, including HSC. To investigate the feasibility of targeting CD47 as a therapeutic strategy, we utilized a normal C57BL/6 mouse model to examine an anti-mouse CD47-blocking monoclonal antibody (MIAP301). Wild-type C57BL/6 mice were administered daily by intraperitoneal injections with $400 \mu \mathrm{g}$ of anti-mouse CD47 antibody for 14 days and follow-up for 28 days. Complete blood counts showed that white blood cell count, red blood cell count, and hemoglobin level were temporarily decreased in the anti-CD47 antibody-treated mice (Figures 6A-C). There was no evidence of thrombocytopenia (Figure 6D). In another experiment using normal C57BL/6 mouse models established as above, mice were sacrificed on day 0 , day 14 , and day 28. Bone marrow analysis showed no difference in total cellularity (data not shown) and percentage of $\mathrm{Lin}^{-} \mathrm{Kit}^{+} \mathrm{Sca}^{+}$ HSCs (Figures 6E,F). H\&E staining of mouse tissues showed no pathological evidence of lung, liver, brain, spleen, or kidney damage (Figure S6 in Supplementary Material). These results suggest that targeting CD47 with a blocking monoclonal antibody generates no significant toxicity and is a viable therapeutic strategy.

\section{DISCUSSION}

CD47 is involved in the regulation of macrophages' phagocytosis to prevent host cells from being eliminated (29). The mechanism of CD47-regulating phagocytosis is through its interaction with the protein receptor $\operatorname{SIRP} \alpha$ on macrophages $(17,30,31)$. HSCs and LSCs escape from macrophage's phagocytosis through
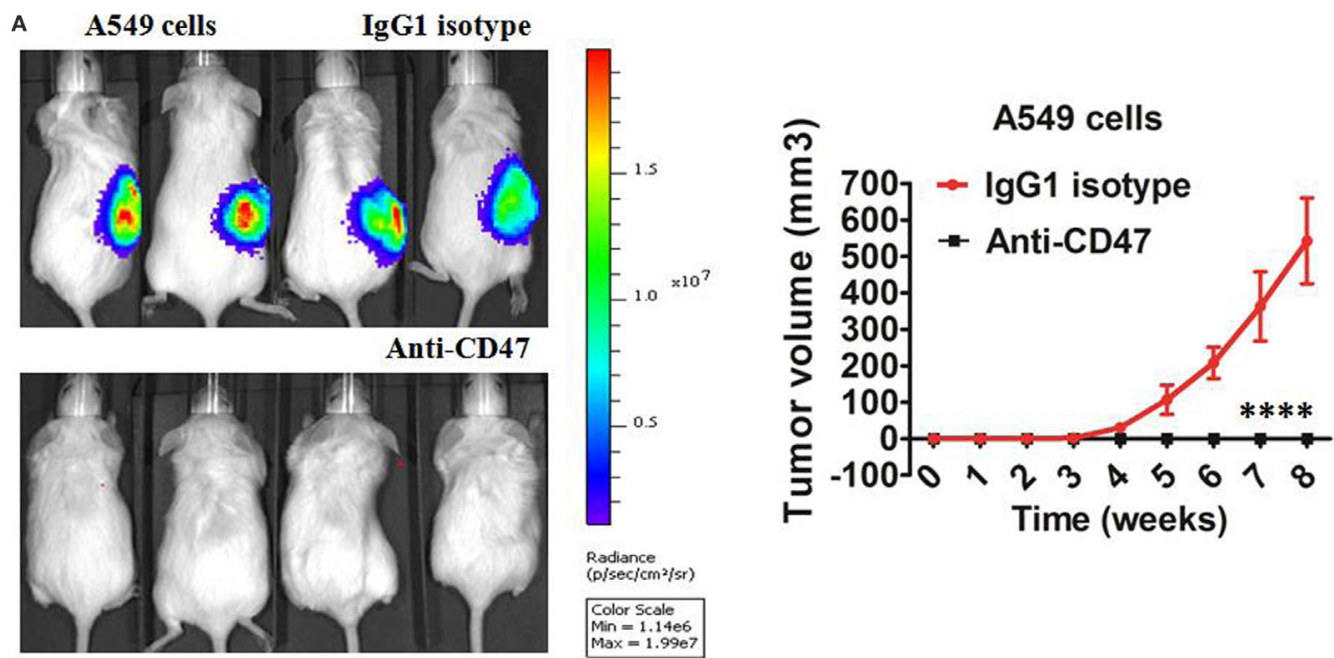

B NCI-H520 CSCs IgG1 isotype
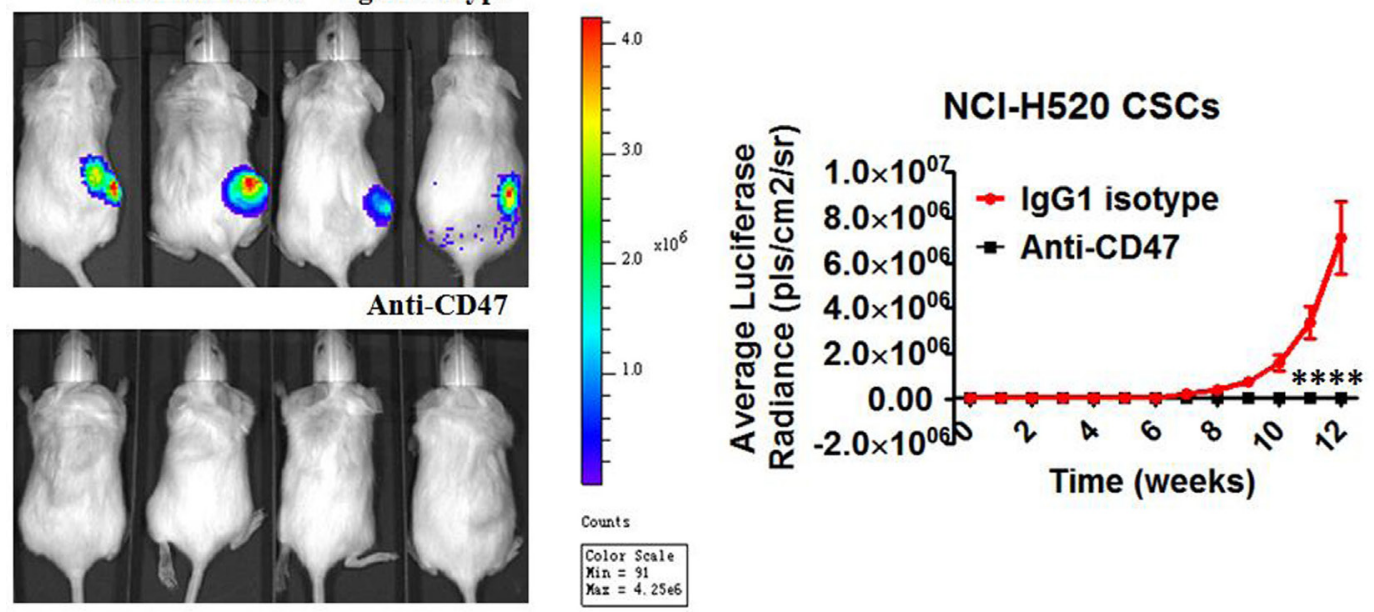

FIGURE 4 | Continued 

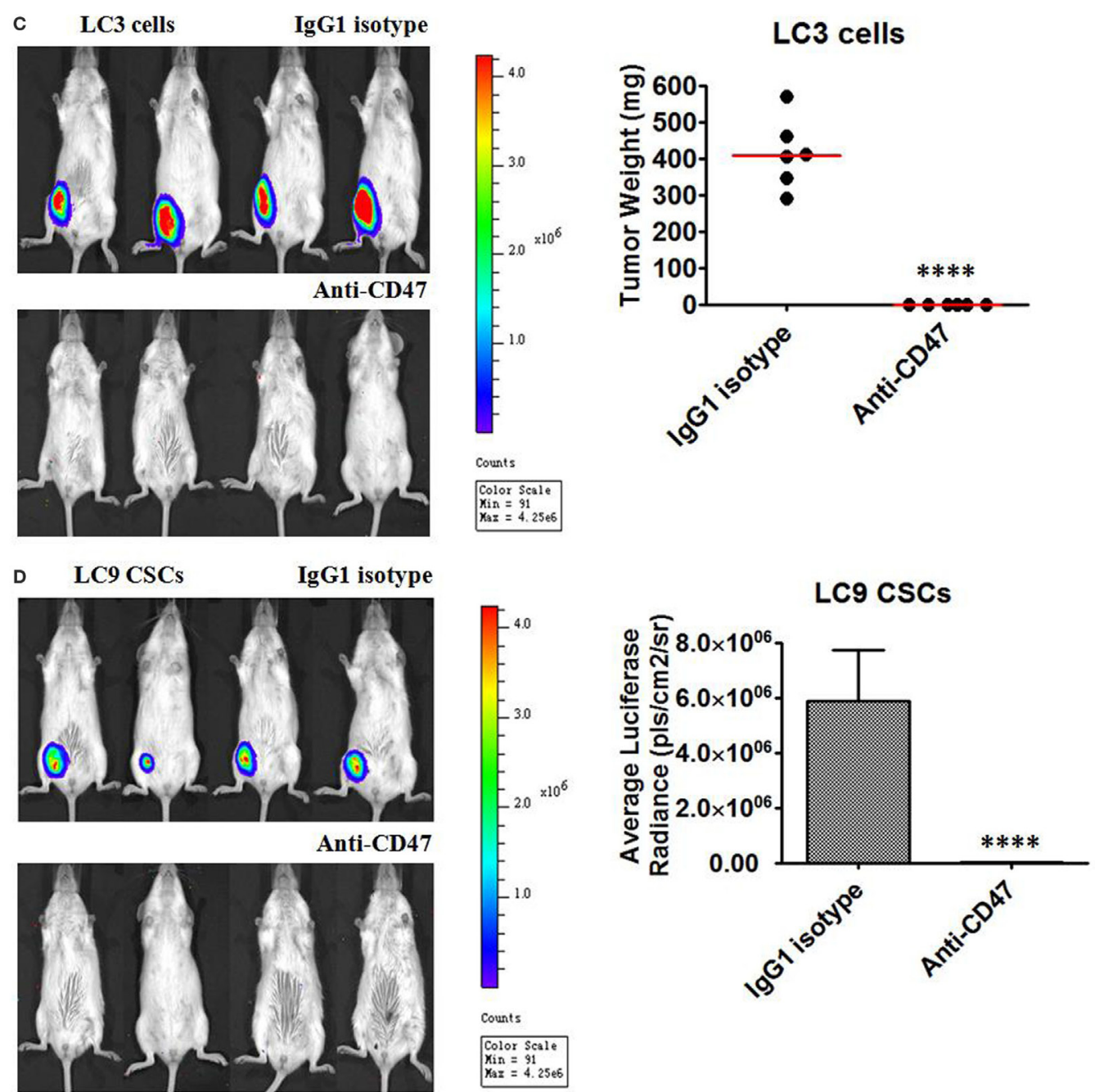

FIGURE 4 | Continued

Ex vivo coating of lung cancer cells and lung cancer stem cells (CSCs) with an anti-CD47 antibody inhibits tumor engraftment. (A-D) Luciferaseexpressing lung cancer cells [A549 cell line cells and primary LC3 tumor cells from a de novo small cell lung carcinoma (SCLC) patient of phase IIB] and lung CSCs [NCl-H520 cell line CSCs and primary LC9 CSCs from a de novo adenocarcinoma patient of phase IIIA] were precoated with IgG1 isotype control antibody or anti-human CD47 B6H12.2 antibody in vitro. NOD/SCID mice transplanted with the A549 cells (A), NCI-H520 CSCs (B), primary LC3 cells (C), or primary LC9 CSCs (D) were subject to bioluminescent imaging. Bioluminescence for A549 cells, NCl-H520 CSCs, LC3 cells, and LC9 CSCs engrafted mice was quantified ( $n=6$ per antibody condition). No tumor engraftment was observed in mice transplanted with anti-CD47-coated cells, in contrast to the 100\% engraftment with IgG-coated cells $(P<0.0001)$, for all tested cells including A549 cells (A), NCl-H520 CSCs (B), LC3 cells (C), and LC9 CSCs (D). Data are represented as mean \pm SD.

upregulating CD47 expression level $(21,22)$. Hence, CD47 serves as a target in the treatment of acute mylocytic leukemia (AML) by utilizing antibodies against CD47 to facilitate AML elimination by macrophages, which results in the blockade of inhibitory CD47-SIRP $\alpha$ signaling $(21,22)$. Thus far, CD47 has been found to be expressed on multiple human tumors, and anti-CD47 antibody can inhibit growth of these tumors in vitro and in vivo $(23,26,32-38)$. CD47 blockade is considered as another immune checkpoint therapy for cancer (39). However, it is unclear how CD47 is involved in lung cancer initiation and progression. In this study, we indicate that higher expression of
CD47 is also the mechanism used by lung cancer cells, especially lung CSCs, to escape phagocytosis. Blocking antibodies that dismiss the interaction between CD47 and SIRP $\alpha$ enable the phagocytosis of lung cancer cells and CSCs in vitro and inhibited tumor growth in several xenotransplantation models. In addition, the identification of CD47 and CD133 levels as prognostic factors could be incorporated into standard clinical prognostic considerations across multiple subtypes of lung cancer and may be useful in risk-adapted therapy decision-making. These results establish CD47 as a therapeutic target in lung cancer, as well as a therapeutic target in lung CSCs. 
A A549 cells

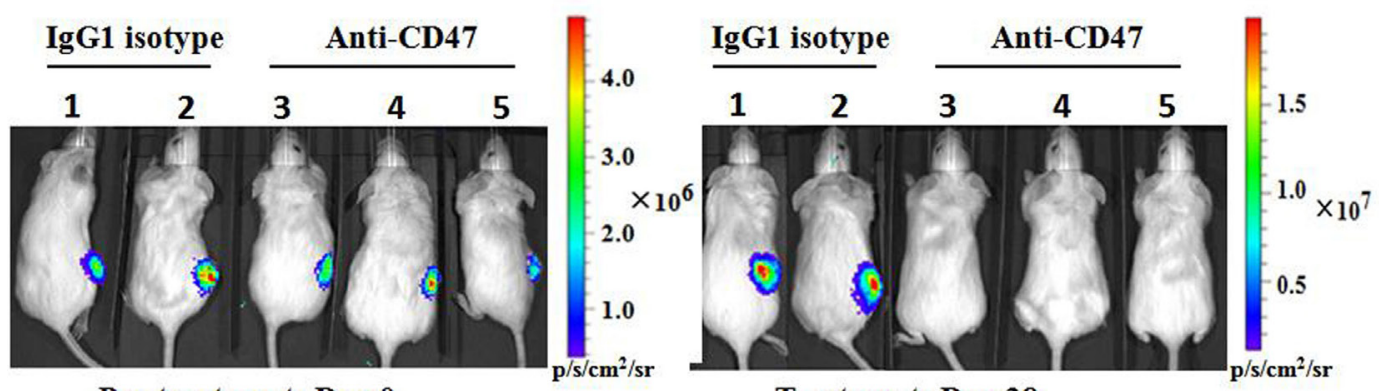

Pre-treatment: Day 0

Treatment: Day 28

B $\quad$ A549 cells
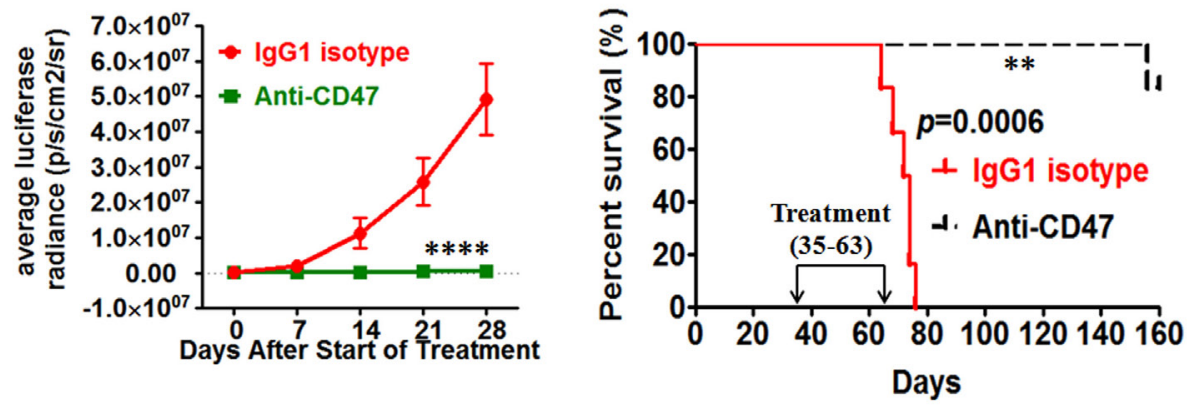

C

NCI-H520 CSCs

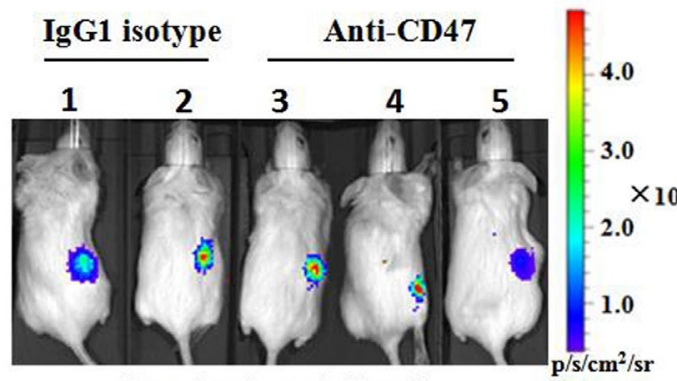

Pre-treatment: Day 0

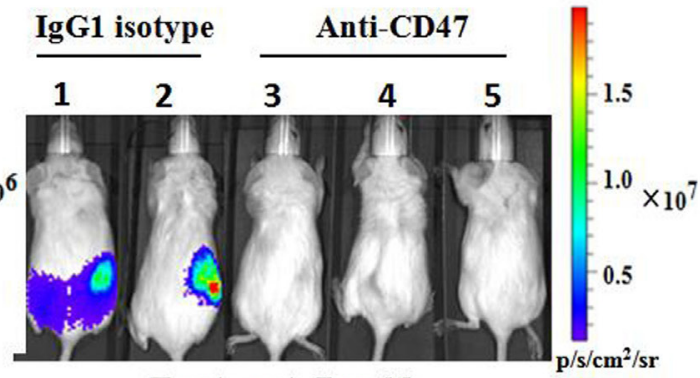

Treatment: Day 28
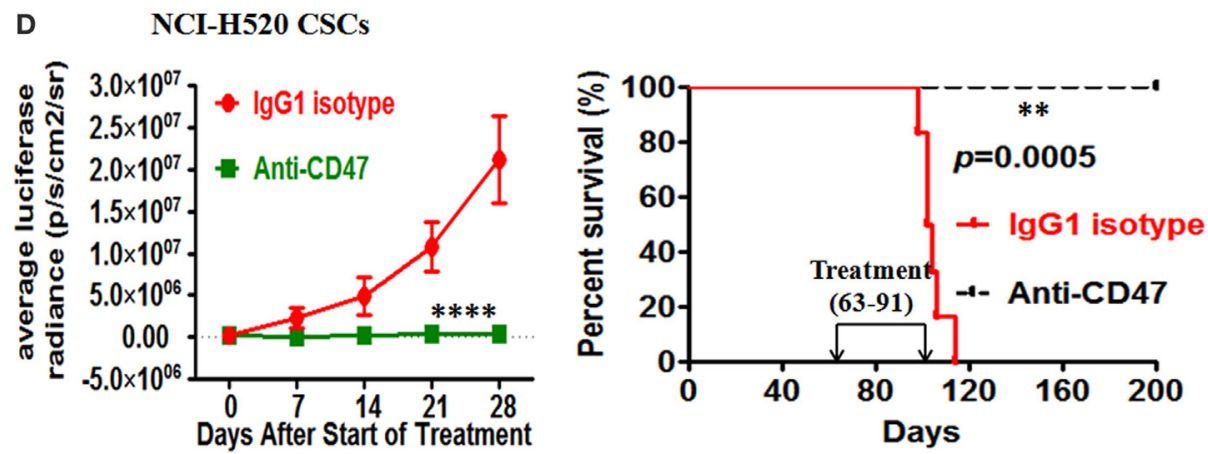

FIGURE 5 | Continued 
E

LC3 Cells

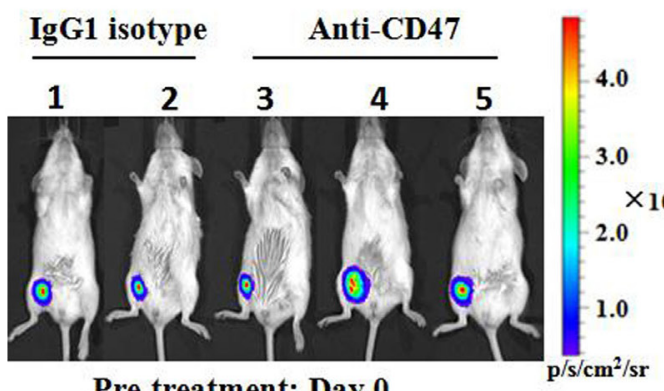

Pre-treatment: Day 0

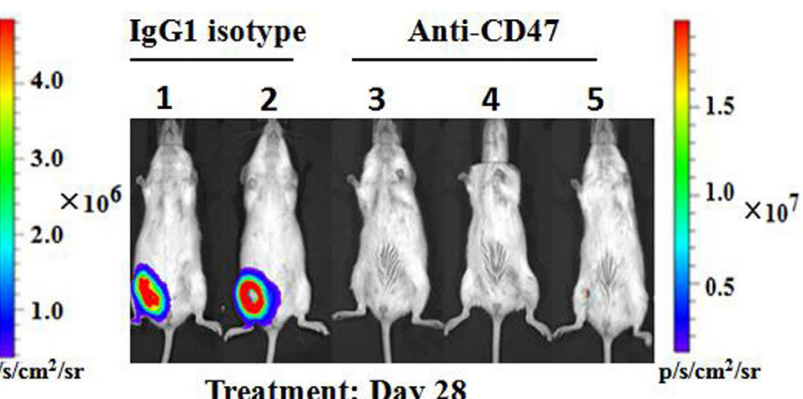

Treatment: Day 28
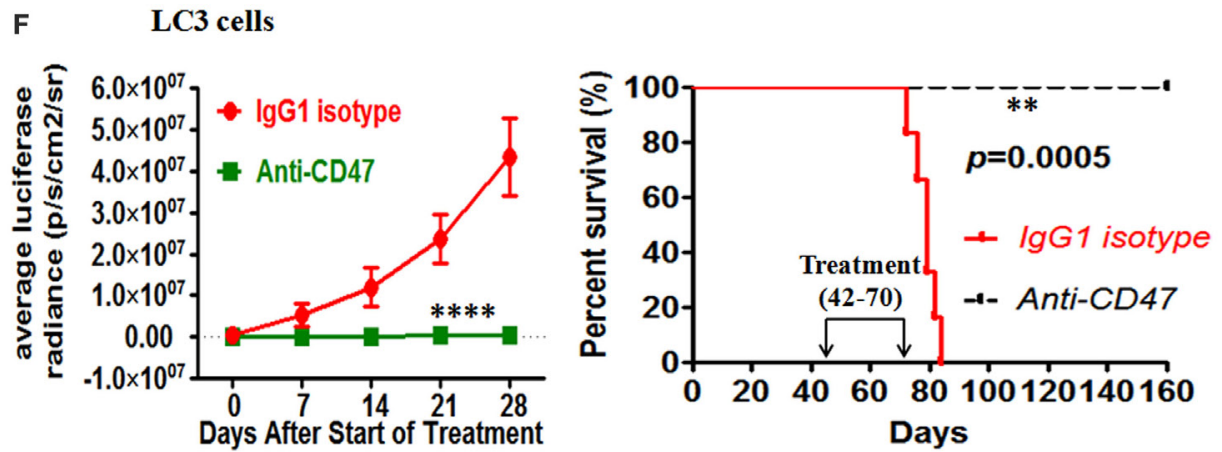

G

LC9 CSCs

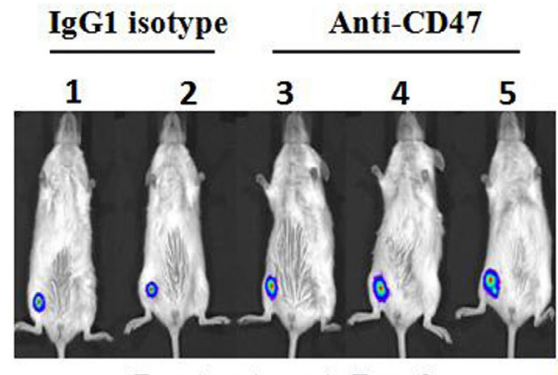

Pre-treatment: Day 0

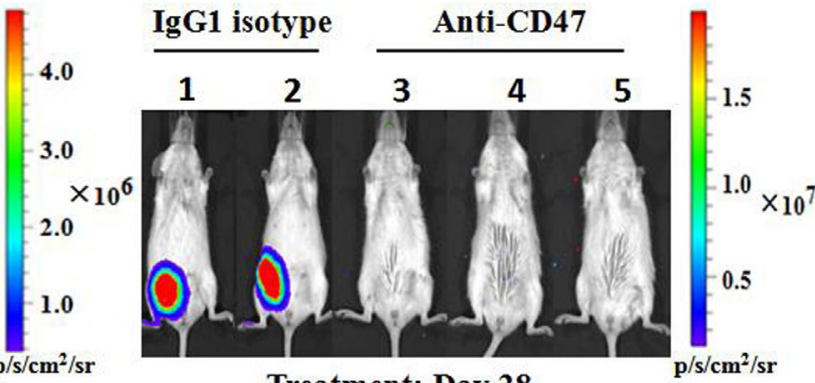

Treatment: Day 28
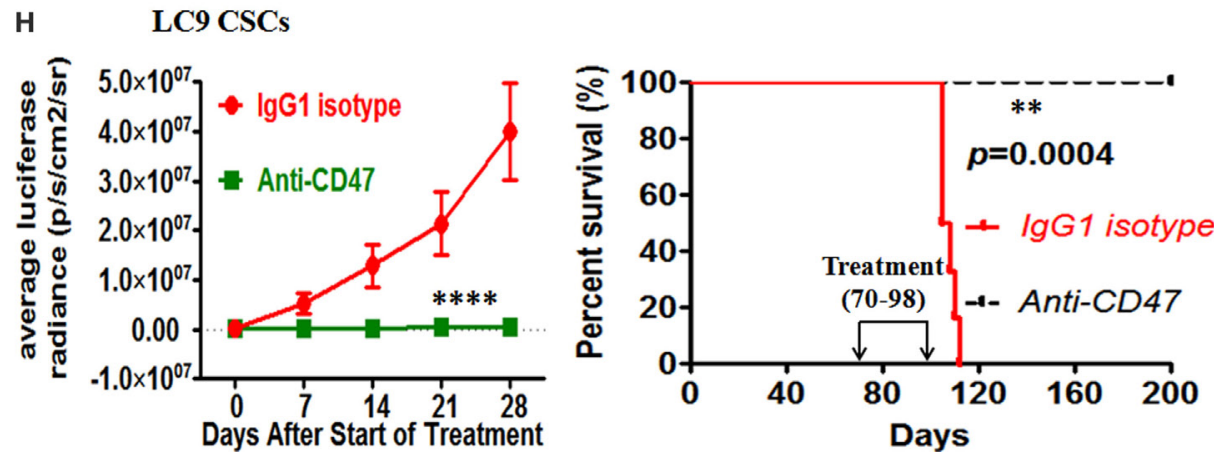

FIGURE 5 | Continued 
FIGURE 5 | Continued

Therapy with anti-CD47 antibody eliminates lung cancer cells and lung cancer stem cells (CSCs) in xenotransplant models. (A) Luciferase-expressing A549 cells were transplanted subcutaneously into NOD/SCID mice. When palpable tumors ( 100 $\left.\mathrm{mm}^{3}\right)$ formed, mice started to be treated with the lgG1 isotype antibody or anti-CD47 antibody ( $n=6$ per treatment group). Luciferase imaging of representative mice from each treatment group was shown before (day 0 ) and during (day 28) treatment (A). Average bioluminescence and improved survival were shown (B). (C) NOD/SCID mice were transplanted subcutaneously with luciferase-expressing NCl-H520 CSCs. When palpable tumors ( 100 mm³) formed, mice started to be treated with the lgG1 isotype antibody or anti-CD47 antibody ( $n=6$ per treatment group). Luciferase imaging of representative mice from pretreatment and 28 days posttreatment were shown (C). Average bioluminescence and improved survival were shown (D). (E) NOD/SCID mice were transplanted subcutaneously with luciferase-expressing primary LC3 tumor cells. When palpable tumors $\left(\sim 100 \mathrm{~mm}^{3}\right)$ formed, mice started to be treated with the lgG1 isotype antibody or anti-CD47 antibody ( $n=6$ per treatment group). Luciferase imaging of representative mice from pretreatment and 28 days posttreatment were shown (E). Average bioluminescence and improved survival were shown (F). (G) Luciferaseexpressing primary LC9 CSCs were transplanted subcutaneously into the NOD/SCID mice. When palpable tumors ( 100 mm $\left.{ }^{3}\right)$ formed, mice started to be treated with the IgG1 isotype antibody or anti-CD47 antibody ( $n=6$ per treatment group). Luciferase imaging of representative mice from pretreatment and 28 days posttreatment were shown (G). Average bioluminescence and improved survival were shown $\mathbf{( H )}{ }^{\star \star \star \star \star} P<0.0001$.

A

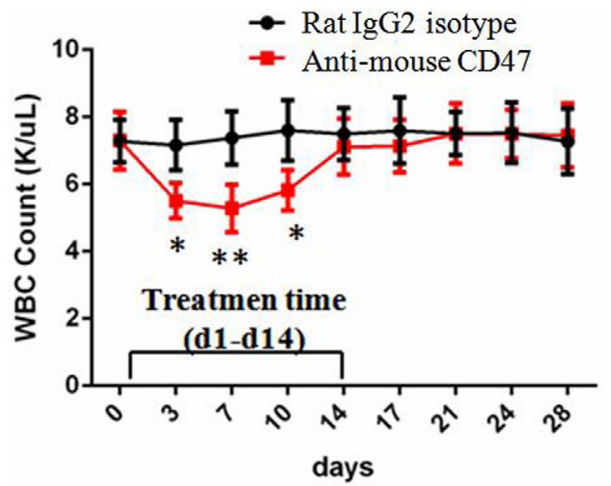

C

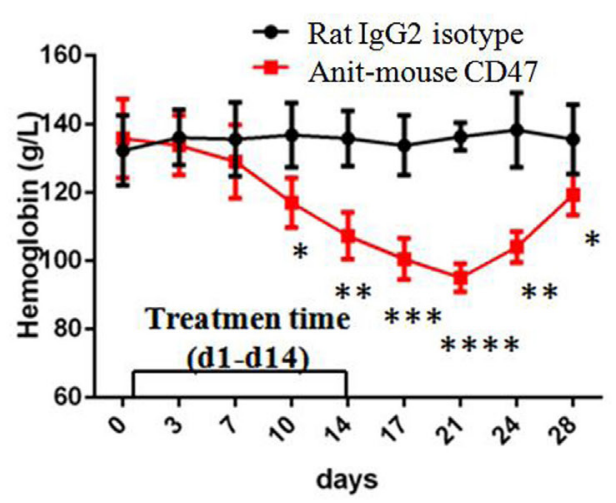

E

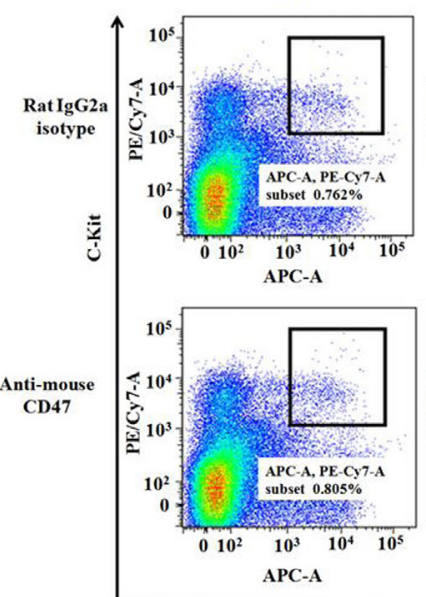

d14
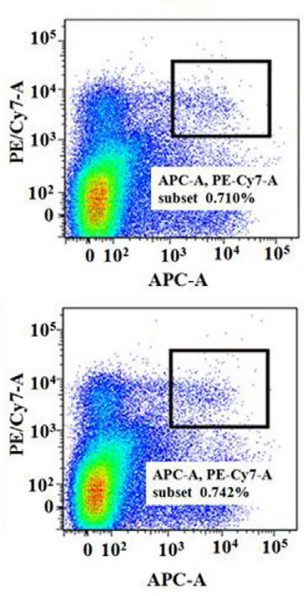

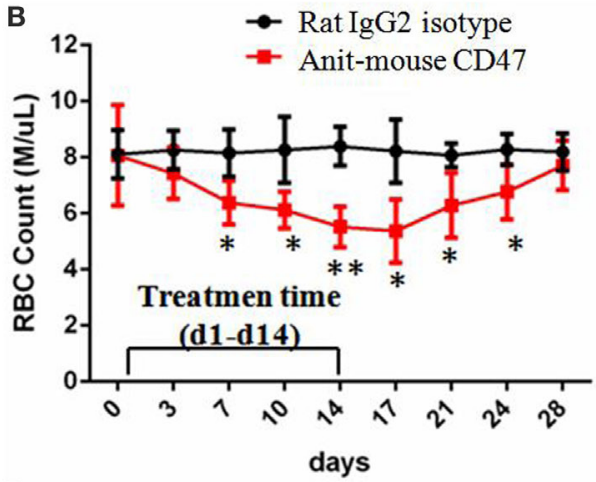

D
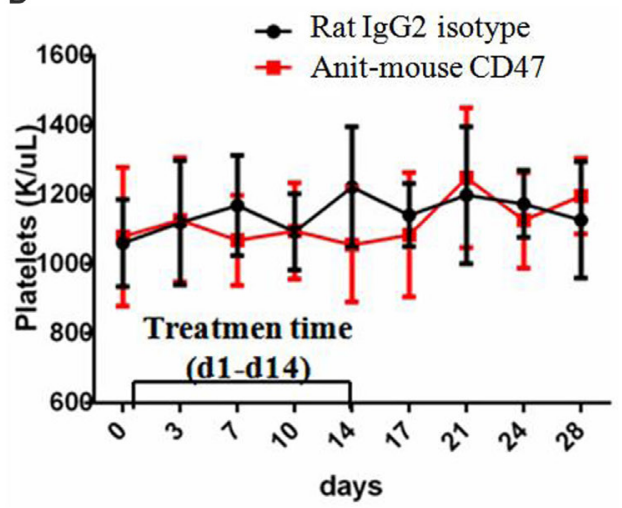

d28
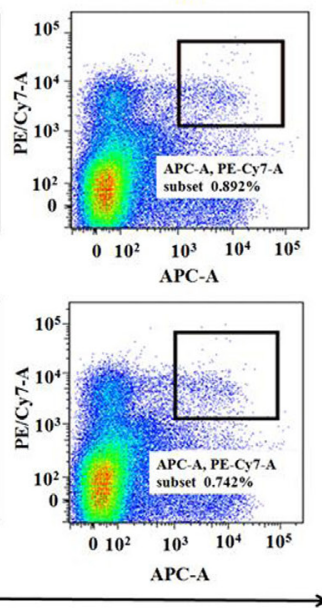

Sca-1 


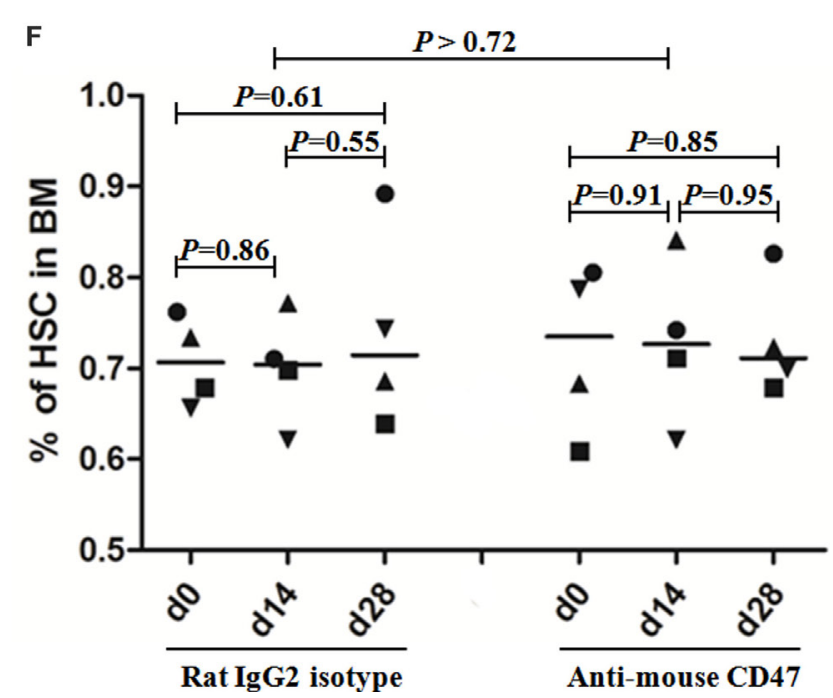

FIGURE 6 | Anti-CD47 antibody exhibited no significant toxic effect except temporary white blood cell reduction and anemia. (A-D) Rat lgG2 isotype antibody or anti-mouse CD47 MIAP301 antibody was intraperitoneally injected into normal C57BL/6 mice at the dose of $400 \mu \mathrm{g}$ daily from day 1 to day 14 ( $n=4$ per treatment group). These mice were followed up till day 28. White blood cell count (A), red blood cell count (B), and hemoglobin level (C) were temporarily decreased in anti-mouse CD47 group compared to IgG2 isotype group. Platelets count (D) has no difference between the two groups. (E-F) Mouse models were created as (A-D). Bone marrow from these mice was aspirated at day 0, day 14, and day 28 and indicated no effect of treatment on the frequency of Lin-Kit ${ }^{+}$Sca ${ }^{+}$ hematopoietic stem cell (HSC) in the bone marrow. (E) Representative FACS plots are shown. (F) No differences in the percentage of HSC at day 0, day 14, and day 28 were observed with either control lgG or anti-mouse CD47.

The toxicity of anti-CD47 antibody should be concerned when we translate this therapy to human application. CD47 is expressed on normal (non-tumor) cells at varying levels, but highly on tumor cells (16). In our study, we show that normal C57BL/6 mice treated with therapeutic doses of anti-mouse CD47-blocking antibody had no significant toxic effect except temporary anemia and white blood cells reduction (Figure 6; Figure S6 in Supplementary Material). The similar results were obtained in previous studies $(22,26)$. In these reports, mice were administered with 200-400 $\mu \mathrm{g}$ doses of anti-CD47 antibodies that may be in far excess of the minimal effective dose. Moreover, anti-CD47 antibody could not induce phagocytosis of non-cancer or normal cells in vitro $(22,27)$. These findings suggest that normal healthy cells are not subject to phagocytosis by phagocytes, because of lack a secondary prophagocytic "eat me" signaling, even deficiency of CD47-SIRP $\alpha$ signaling. Calreticulin and phosphatidylserine, as cell surface prophagocytic signals, have been identified $(40,41)$. Calreticulin can interact with LDL-receptor-related protein 1 on macrophages and is required for the phagocytosis of tumor cell lines, whose function is to neutralize $\mathrm{CD} 47-\mathrm{SIRP} \alpha$ interaction (42). Calreticulin is expressed on cell surfaces of human leukemias, lymphomas, and solid cancers, but not on non-tumor or normal cell surfaces (38). Those prophagocytic signals on tumor cells may provide a therapeutic window to treatment with antiCD47 antibodies without causing phagocytosis of normal cells that lack these "eat me" signals.

Here, we also detected the efficacy of anti-CD47 antibody to inhibit lung cancer cell growth as a monotherapy. In our study, anti-human CD47 antibody remarkably enhanced the phagocytosis of lung cancer cell lines and primary tumor cells in vitro
(Figures 3A-C) and significantly inhibited tumor growth in lung cancer cell and primary tumor cell xenotransplantation models (Figures 5A,B,E,F). To investigate whether NK cells could mediate tumor elimination by anti-CD47 antibody in vitro, we utilized human NK cells $\left(\mathrm{CD}^{-} \mathrm{CD}^{-} 6^{+} \mathrm{CD}^{+}\right)$as effectors. Anti-CD47 antibody did not induce increased ADCC of lung cancer cell line cells or primary patients tumor cells compared to IgG1 isotype control. However, anti-CD47 antibody caused increased ADCC of these cells compared to isotype control when we repeated these assays with mouse $\mathrm{NK}$ cells $\left(\mathrm{CD}^{-} \mathrm{DX} 5^{+}\right)$as effectors (Figures 3F,G). This indicated that NK cell was a potential contributor to tumor suppression in anti-CD47 antibody antitumor, and the antitumor effect obtained in the xenograft model may in part be mediated by mouse NK cells. In a previous study, anti-CD47 antibody can inhibit breast cancer, bladder cancer, ovarian cancer, colorectal cancer, and glioblastoma growth as a monotherapy (26). Together with our results and previous study, it suggested that CD47 is a promising therapeutic target in various types of solid tumor cells.

Cancer stem cells are a small subgroup of cancer cells that structure a reservoir of self-sustaining cells with the characteristic ability to self-renew and maintain the tumor mass $(4,43)$. The CSC model has been successfully used to explain events in tumor initiation, development, metastasis, relapse, and ineffectiveness of conventional cancer therapies. Conventional treatments directed against the bulk of the tumor cells may produce remarkable initial responses, but they are unlikely to result in long-term remissions if the rare CSCs are not targeted and escape (44). Here, we selected CD133 as the lung CSC marker (3-6) and purified CSCs from the luciferase-expressing NCI-H520 cell line and primary tumor 
cells by FACS. Then, we evaluated the efficacy of anti-CD47 antibody to inhibit lung CSCs as a monotherapy. In our study, anti-human CD47 antibody remarkably enhanced the phagocytosis of lung CSCs from the cell line and primary tumors in vitro (Figures 3D-F) and significantly inhibited tumor growth in the two lung CSCs xenotransplantation models (Figures 5C,D,G,H). In a previous report, anti-CD47 antibody can inhibit LSCs, breast CSCs, and bladder CSCs as a monotherapy $(22,26,28)$. These results suggested that $\mathrm{CD} 47$ can be used as a therapeutic target to eliminate solid tumor CSCs.

In conclusion, we found that CD47 is expressed on lung cancer cells and lung CSCs, and CD47 and CD133 levels as prognostic factors can be useful in risk-adapted therapy decision-making of lung cancer patients. We have validated an important function of CD47 on lung cancer cells, especially lung CSCs, as a "don't-eat-me" signal. We have also indicated that anti-CD47blocking antibody is effective for treating human lung cancer and CSCs in vitro and in vivo. We anticipate that CD47 can be as a therapeutic target against solid tumors cells and their CSCs.

\section{ETHICS STATEMENT}

Lung cancer tissue specimens were obtained from consented patients as approved by National Clinical Research Center of Cancer of China Review Board protocols. The experimental procedures involving human data were reviewed and approved by the Ethics Committee of National Clinical Research Center

\section{REFERENCES}

1. Jordan CT, Guzman ML, Noble M. Cancer stem cells. N Engl J Med (2006) 355:1253-61. doi:10.1056/NEJMra061808

2. Reya T, Morrison SJ, Clarke MF, Weissman IL. Stem cells, cancer, and cancer stem cells. Nature (2001) 414:105-11. doi:10.1038/35102167

3. Pine SR, Ryan BM, Varticovski L, Robles AI, Harris CC. Microenvironmental modulation of asymmetric cell division in human lung cancer cells. Proc Natl Acad Sci U S A (2010) 107:2195-200. doi:10.1073/pnas.0909390107

4. O'Brien CA, Kreso A, Jamieson CH. Cancer stem cells and self-renewal. Clin Cancer Res (2010) 16:3113-20. doi:10.1158/1078-0432.CCR-09-2824

5. Bertolini G, Roz L, Perego P, Tortoreto M, Fontanella E, Gatti L, et al. Highly tumorigenic lung cancer CD133+ cells display stem-like features and are spared by cisplatin treatment. Proc Natl Acad Sci U S A (2009) 106:16281-6. doi:10.1073/pnas.0905653106

6. Eramo A, Lotti F, Sette G, Pilozzi E, Biffoni M, Di Virgilio A, et al. Identification and expansion of the tumorigenic lung cancer stem cell population. Cell Death Differ (2008) 15:504-14. doi:10.1038/sj.cdd.4402283

7. Ginestier C, Hur MH, Charafe-Jauffret E, Monville F, Dutcher J, Brown M, et al. ALDH1 is a marker of normal and malignant human mammary stem cells and a predictor of poor clinical outcome. Cell Stem Cell (2007) 1:555-67. doi:10.1016/j.stem.2007.08.014

8. Al-Hajj M, Wicha MS, Benito-Hernandez A, Morrison SJ, Clarke MF. Prospective identification of tumorigenic breast cancer cells. Proc Natl Acad Sci U S A (2003) 100:3983-8. doi:10.1073/pnas.0530291100

9. Singh SK, Hawkins C, Clarke ID, Squire JA, Bayani J, Hide T, et al. Identification of human brain tumour initiating cells. Nature (2004) 432:396-401. doi:10.1038/nature03128

10. Ricci-Vitiani L, Lombardi DG, Pilozzi E, Biffoni M, Todaro M, Peschle C, et al. Identification and expansion of human colon-cancer-initiating cells. Nature (2007) 445:111-5. doi:10.1038/nature05384

11. O'Brien CA, Pollett A, Gallinger S, Dick JE. A human colon cancer cell capable of initiating tumour growth in immunodeficient mice. Nature (2007) 445:106-10. doi:10.1038/nature05372 of Cancer of China. All subjects gave written informed consent in accordance with the Declaration of Helsinki. All experiments involving mice were performed according to Tianjin Medical University Cancer Institute and Hospital animal guidelines. The experimental protocol involving animals were reviewed and approved by the Ethics committee of Tianjin Medical University Cancer Institute and Hospital.

\section{AUTHOR CONTRIBUTIONS}

LL, LZ, HL, and XR designed the experiments. LL, SW, and XR wrote the manuscript. LL, LZ, LY (Lin Yang), JY, LY (Lili Yang), CY, FW, QS, RL, and HZ performed the experiments and analyzed data. LL, FY, HJ, JW, and LZ provided patient samples and clinical data.

\section{FUNDING}

This research is supported by the National Natural Science Funds (No. 81572913), the National Key Technologies R\&D Program (No. 2015BAI12B12), and the Chinese Postdoctoral Science Foundation (No. 20110490790 and No. 2012T50222).

\section{SUPPLEMENTARY MATERIAL}

The Supplementary Material for this article can be found online at http://journal.frontiersin.org/article/10.3389/fimmu. 2017.00404/full\#supplementary-material.

12. Prince ME, Sivanandan R, Kaczorowski A, Wolf GT, Kaplan MJ, Dalerba P, et al. Identification of a subpopulation of cells with cancer stem cell properties in head and neck squamous cell carcinoma. Proc Natl Acad Sci U S A (2007) 104:973-8. doi:10.1073/pnas.0610117104

13. Li C, Heidt DG, Dalerba P, Burant CF, Zhang L, Adsay V, et al. Identification of pancreatic cancer stem cells. Cancer Res (2007) 67:1030-7. doi:10.1158/00085472.CAN-06-2030

14. Patrawala L, Calhoun T, Schneider-Broussard R, Li H, Bhatia B, Tang S, et al. Highly purified CD44+ prostate cancer cells from xenograft human tumors are enriched in tumorigenic and metastatic progenitor cells. Oncogene (2006) 25:1696-708. doi:10.1038/sj.onc.1209327

15. Schatton T, Murphy GF, Frank NY, Yamaura K, Waaga-Gasser AM, Gasser M, et al. Identification of cells initiating human melanomas. Nature (2008) 451:345-9. doi:10.1038/nature06489

16. Brown EJ, Frazier WA. Integrin-associated protein (CD47) and its ligands. Trends Cell Biol (2001) 11:130-5. doi:10.1016/S0962-8924(00)01906-1

17. Jiang P, Lagenaur CF, Narayanan V. Integrin-associated protein is a ligand for the P84 neural adhesion molecule. J Biol Chem (1999) 274:559-62. doi:10.1074/jbc.274.2.559

18. Oldenborg PA. Role of CD47 in erythroid cells and in autoimmunity. Leuk Lymphoma (2004) 45:1319-27. doi:10.1080/1042819042000201989

19. Oldenborg PA, Gresham HD, Lindberg FP. CD47-signal regulatory protein alpha (SIRPalpha) regulates Fcgamma and complement receptormediated phagocytosis. JExp Med (2001) 193:855-62. doi:10.1084/ jem.193.7.855

20. Blazar BR, Lindberg FP, Ingulli E, Panoskaltsis-Mortari A, Oldenborg PA, Iizuka K, et al. CD47 (integrin-associated protein) engagement of dendritic cell and macrophage counterreceptors is required to prevent the clearance of donor lymphohematopoietic cells. J Exp Med (2001) 194:541-9. doi:10.1084/ jem.194.4.541

21. Jaiswal S, Jamieson CH, Pang WW, Park CY, Chao MP, Majeti R, et al. CD47 is upregulated on circulating hematopoietic stem cells and leukemia cells to avoid phagocytosis. Cell (2009) 138:271-85. doi:10.1016/j.cell.2009. 05.046 
22. Majeti R, Chao MP, Alizadeh AA, Pang WW, Jaiswal S, Gibbs KD Jr, et al. CD47 is an adverse prognostic factor and therapeutic antibody target on human acute myeloid leukemia stem cells. Cell (2009) 138:286-99. doi:10.1016/ j.cell.2009.05.045

23. Krampitz GW, George BM, Willingham SB, Volkmer JP, Weiskopf K, Jahchan N, et al. Identification of tumorigenic cells and therapeutic targets in pancreatic neuroendocrine tumors. Proc Natl Acad Sci U S A (2016) 113:4464-9. doi:10.1073/pnas.1600007113

24. McCracken MN, Cha AC, Weissman IL. Molecular pathways: activating T cells after cancer cell phagocytosis from blockade of CD47 "don't eat me" signals. Clin Cancer Res (2015) 21:3597-601. doi:10.1158/1078-0432.CCR14-2520

25. Weiskopf K, Ring AM, Ho CC, Volkmer JP, Levin AM, Volkmer AK, et al. Engineered SIRP $\alpha$ variants as immunotherapeutic adjuvants to anticancer antibodies. Science (2013) 341:88-91. doi:10.1126/science.1238856

26. Willingham SB, Volkmer JP, Gentles AJ, Sahoo D, Dalerba P, Mitra SS, et al. The CD47-signal regulatory protein alpha (SIRPa) interaction is a therapeutic target for human solid tumors. Proc Natl Acad Sci U S A (2012) 109:6662-7. doi:10.1073/pnas.1121623109

27. Chao MP, Alizadeh AA, Tang C, Myklebust JH, Varghese B, Gill S. Anti-CD47 antibody synergizes with rituximab to promote phagocytosis and eradicate non-Hodgkin lymphoma. Cell (2010) 142:699-713. doi:10.1016/j. cell.2010.07.044

28. Chan KS, Espinosa I, Chao M, Wong D, Ailles L, Diehn M, et al. Identification, molecular characterization, clinical prognosis, and therapeutic targeting of human bladder tumor-initiating cells. Proc Natl Acad Sci U S A (2009) 106:14016-21. doi:10.1073/pnas.0906549106

29. Jaiswal S, Chao MP, Majeti R, Weissman IL. Macrophages as mediators of tumor immunosurveillance. Trends Immunol (2010) 31:212-9. doi:10.1016/ j.it.2010.04.001

30. Seiffert M, Brossart P, Cant C, Cella M, Colonna M, Brugger W, et al. Signalregulatory protein alpha (SIRPalpha) but not SIRPbeta is involved in T-cell activation, binds to CD47 with high affinity, and is expressed on immature CD34(+)CD38(-) hematopoietic cells. Blood (2001) 97:2741-9. doi:10.1182/ blood.V97.9.2741

31. Barclay AN, Brown MH. The SIRP family of receptors and immune regulation. Nat Rev Immunol (2006) 6:457-64. doi:10.1038/nri1859

32. Chao MP, Weissman IL, Majeti R. The CD47-SIRP $\alpha$ pathway in cancer immune evasion and potential therapeutic implications. Curr Opin Immunol (2012) 24:225-32. doi:10.1016/j.coi.2012.01.010

33. Chao MP, Tang C, Pachynski RK, Chin R, Majeti R, Weissman IL. Extranodal dissemination of non-Hodgkin lymphoma requires CD47 and is inhibited by anti-CD47 antibody therapy. Blood (2011) 118:4890-901. doi:10.1182/ blood-2011-02-338020

34. Chao MP, Alizadeh AA, Tang C, Jan M, Weissman-Tsukamoto R, Zhao F, et al. Therapeutic antibody targeting of CD47 eliminates human acute lymphoblastic leukemia. Cancer Res (2011) 71:1374-84. doi:10.1158/0008-5472. CAN-10-2238
35. Cioffi M, Trabulo S, Hidalgo M, Costello E, Greenhalf W, Erkan M. Inhibition of CD47 effectively targets pancreatic cancer stem cells via dual mechanisms. Clin Cancer Res (2015) 21:2325-37. doi:10.1158/1078-0432.CCR-14-1399

36. Steinert G, Schölch S, Niemietz T, Iwata N, García SA, Behrens B, et al. Immune escape and survival mechanisms in circulating tumor cells of colorectal cancer. Cancer Res (2014) 74:1694-704. doi:10.1158/0008-5472.CAN-13-1885

37. Pang WW, Pluvinage JV, Price EA, Sridhar K, Arber DA, Greenberg PL, et al. Hematopoietic stem cell and progenitor cell mechanisms in myelodysplastic syndromes. Proc Natl Acad Sci U S A (2013) 110:3011-6. doi:10.1073/ pnas. 1222861110

38. Kaur S, Elkahloun AG, Singh SP, Chen QR, Meerzaman DM, Song T, et al. A function-blocking CD47 antibody suppresses stem cell and EGF signaling in triple-negative breast cancer. Oncotarget (2016) 7:10133-52. doi:10.18632/ oncotarget.7100

39. Vonderheide RH. CD47 blockade as another immune checkpoint therapy for cancer. Nat Med (2015) 21:1122-3. doi:10.1038/nm.3965

40. Ogden CA, deCathelineau A, Hoffmann PR, Bratton D, Ghebrehiwet B, Fadok VA, et al. C1q and mannose binding lectin engagement of cell surface calreticulin and CD91 initiates macropinocytosis and uptake of apoptotic cells. J Exp Med (2001) 194:781-95. doi:10.1084/jem.194.6.781

41. Hoffmann PR, deCathelineau AM, Ogden CA, Leverrier Y, Bratton DL, Daleke DL, et al. Phosphatidylserine (PS) induces PS receptor-mediated macropinocytosis and promotes clearance of apoptotic cells. J Cell Biol (2001) 155:649-59. doi:10.1083/jcb.200108080

42. Gardai SJ, McPhillips KA, Frasch SC, Janssen WJ, Starefeldt A, MurphyUllrich JE, et al. Cell-surface calreticulin initiates clearance of viable or apoptotic cells through trans-activation of LRP on the phagocyte. Cell (2005) 123:321-34. doi:10.1016/j.cell.2005.08.032

43. Clarke MF, Dick JE, Dirks PB, Eaves CJ, Jamieson CH, Jones DL, et al. Cancer stem cells - perspectives on current status and future directions: AACR Workshop on cancer stem cells. Cancer Res (2006) 66:9339-44. doi:10.1158/0008-5472.CAN-06-3126

44. Visvader JE. Cells of origin in cancer. Nature (2011) 469:314-22. doi:10.1038/ nature09781

Disclaimer: This study has not been presented in part anywhere.

Conflict of Interest Statement: The authors declare that the research was conducted in the absence of any commercial or financial relationships that could be construed as a potential conflict of interest.

Copyright (c) 2017 Liu, Zhang, Yang, Li, Li, Yu, Yang, Wei, Yan, Sun, Zhao, Yang, Jin, Wang, Wang and Ren. This is an open-access article distributed under the terms of the Creative Commons Attribution License (CC BY). The use, distribution or reproduction in other forums is permitted, provided the original author(s) or licensor are credited and that the original publication in this journal is cited, in accordance with accepted academic practice. No use, distribution or reproduction is permitted which does not comply with these terms. 